\title{
INDICIOS DE VIOLENCIA EN YACIMIENTOS DE LA REGIÓN DE MADRID EN EL MARCO DEL CALCOLÍTICO PENINSULAR
}

\author{
SIGNS OF VIOLENCE AT ARCHAEOLOGICAL SITES IN THE MADRID \\ REGION DURING THE IBERIAN CHALCOLITHIC
}

POR

\author{
Corina Liesau*, Patricia Ríos ${ }^{* *}$, Concepción Blasco $^{* * *}$ y José Luis GómeZ ${ }^{* * * *}$
}

\section{Resumen - ABstract}

En el presente trabajo reflexionamos sobre diferentes aspectos relacionados con la violencia intergrupal o interpersonal durante el Calcolítico peninsular a través de algunas evidencias arqueológicas, además de presentar otros registros antropológicos inéditos. Especial atención merecen una serie de lesiones en hueso causadas por actos violentos que han sido documentadas en dos yacimientos calcolíticos madrileños, como son Camino de las Yeseras y Humanejos y al que se le añade otro posible caso encontrado en la necrópolis de Ciempozuelos. Del primer yacimiento se valoran diferentes registros en una fosa con una inhumación múltiple que acoge a un posible grupo familiar asociado a numerosas puntas de flecha y cuya causa de muerte pudo estar en relación con un episodio violento. Mucho más evidentes son las lesiones que presentan otros dos varones campaniformes: un individuo madurosenil de Camino de las Yeseras con una fractura y acusada desviación de los nasales que podría ser un indicio de un enfrentamiento interpersonal, mientras que otro varón adulto de Humanejos fue víctima de un contundente golpe en el frontal ante mortem, posiblemente golpeado con una azuela o hachita de cobre. Estos casos permiten intuir la existencia de conflictos inter o intragrupales más o menos organizados. Por otra parte se justifica la construcción de defensas arquitectónicas en una serie de yacimientos peninsulares, las cuales están asociadas a un considerable número de puntas de proyectil localizadas en sus accesos, tramos de murallas y en talleres próximos a ellas. Durante el Calcolítico, la necesidad de garantizar la seguridad de estas comunidades prehistóricas hace que la producción de las puntas en sílex y posteriormente en metal (Palmela) sean un recurso armamentístico de primer rango, siendo secundario su empleo en las actividades cinegéticas, como quedan avalados por los estudios arqueofaunísticos. También se discute el empleo de útiles habituales recuperados en los horizontes habitacionales como testimonios de actos de violencia, muy probablemente, surgidos por las propias desavenencias cotidianas o intergrupales. Todos estos procesos desembocan en el surgimiento de panoplias armamentísticas en el horizonte campaniforme en el que, aunque con discutida funcionalidad, su exhibición y amortización en las tumbas se hace muy patente.

This study focuses on aspects related to interpersonal or intergroup violence during the Iberian Chalcolithic by discussing some archaeological evidences which have not been thoroughly evaluated to date. Particular attention is given to a series of injuries observed in some burials, which in the light of recent anthropological and paleopathological studies are becoming more numerous and diverse. Besides reviewing some papers and proposals on bone injuries resulting from acts of violence, new documented evidences are offered from the study of two Chalcolithic

\footnotetext{
${ }^{*}$ Profesora titular de Prehistoria de la Universidad Autónoma de Madrid. Facultad de Filosofía y Letras, corina. liesau@uam.es.

** Postdoctoral Researcher Alianza 4 Universidades. Prehistory Department Facultat Filosofia i Lletres, Universitat Autònoma de Barcelona, Patricia.Rios@uab.cat.

*** Catedrática de Prehistoria de la Universidad Autónoma de Madrid. Facultad de Filosofía y Letras, concepcion. blasco@uam.es.

***** Antropólogo físico. C/. Cesar Pastor Llopis, Bq 5, portal 3, 4º-3. 28031 (Madrid), jlgomez@cyii.es.
} 
burials in Madrid: Camino de las Yeseras and Humanejos and related to an old one from the cemetery of Ciempozuelos. In the first of these sites, a multiple inhumation in a pit has been documented. It contains a possible family group associated with flint arrow heads intermingled with the skeletons and they seem to be related to the violent death of the group in a short space of time. Far more striking are the injuries found on two Bell Beaker males, one of them from Camino de las Yeseras, a senile with broken and deviated nasal bones, probably due to an interpersonal conflict. The second example, from Humanejos, is a 30 year old male who was a victim of a major traumatic injury to the forehead ante mortem. It was possibly caused by a copper adze or small axe, due to a face-to-face conflict. Both cases seem to suggest that, interpersonal or intergroup violence during the Iberian Chalcolithic is not infrequent. Also the archaeological record is revealing the existence of defensive architectures in several sites, where a considerable amount of arrow heads have been recovered in entrances, walls and workshops. These circumstances and the increase of arrow heads also in some ditched enclosures could explain their productions as primary defensive and offensive artefacts and later on the emergence of the first copper Palmela arrow heads in Iberia. Otherwise, as the archaeozoological studies of some chalcolithic sites reveal, that the increasing frequency of the flint arrow heads productions are not necessarily related to the rise of hunting activities during the $3^{\text {rd }}$ millennium. It is also discussed the use of some metal tools as weapons during the Bell Beaker horizon as they only appear in household contexts and the functionality of some of the Beaker "package" items from tombs as weapons.

\section{Palabras Clave - Keywords \\ Calcolítico; campaniforme; Península Ibérica; violencia prehistórica; lesiones óseas. \\ Iberian Chalcolític; Bell Beaker; prehistoric violence; bone injuries}

\section{INTRODUCCIÓN}

Aunque en las últimas décadas los estudios paleoantropológicos comienzan a ser relativamente numerosos, su tratamiento suele estar por debajo de otros aspectos de la Arqueología Funeraria como son las estructuras tumbales y las características de los ajuares. Sin embargo, el impulso de la Arqueología antropológica está mitigando esta carencia y la Prehistoria peninsular cuenta ya con una serie de estudios de reconocido interés (Etxeberría y Vegas, 1988; Etxeberría y Herrasti, 2007; Polo et alii 2010: 95-98), no sólo por el mandato reglamentario de algunas Comunidades Autónomas de incorporar los estudios antropológicos en las memorias de los trabajos de campo, sino también por el desarrollo de congresos específicos y de la Arqueometría incorporada en la mayoría de los proyectos de investigación llevados a cabo en los últimos años. Especial énfasis también se ha hecho en que los registros se documenten y se protocolicen "in situ" de forma exhaustiva, incluyendo estudios tafonómicos, diagóstico de paleopatologías, lesiones, deformaciones intencionadas, etc. (Brothwell, 1987; Armendáriz e Irigaray, 1995; Aufderheide y Rodríguez-Martín, 1998; Botella et alii, 2000; Isidro y Malgosa, 2003; Herrerín, 2004; Andrés y Barandiarán, 2004; Ubelaker, 2007; Campillo, 2007; Gómez, 2012).

Mientras que en numerosas regiones de la Península los estudios antropológicos vienen asociados a una larga trayectoria investigadora vinculada al fenómeno megalítico, en el ámbito del Calcolítico madrileño han sido prácticamente inexistentes hasta que se dieron a conocer los trabajos realizados sobre los restos de Camino de las Yeseras (San Fernando de Henares) y de Humanejos (Parla) (Blasco et alii, 2005; Blasco et alii, 2009; Gómez et alii, 2011). Estos trabajos se enmarcan dentro de los objetivos de distintos proyectos y convenios ${ }^{1}$ que nuestro

1 Proyectos y contratos de Investigación: "Economía y ritualidad en el tránsito del III al II Milenio AC. en la Comunidad de Madrid", CCG06-UAM/HUM-0469, dirigido por C. Liesau; "Economía y sociedad durante el Calcolítico de la Meseta: El yacimiento de Camino de las Yeseras (San Fernando de Henares, Madrid). Recursos minerales y actividades", I+D HUM2007-6405, dirigido por J. Baena; "El poblamiento de la Región de Madrid en el III Milenio AC. Nuevas perspectivas a partir de la documentación arqueométrica obtenida de materiales procedentes del yacimiento de Camino de las Yeseras", ref. 1654/09, dirigido por C. Blasco; "Materiales y recursos arqueobiológicos durante el III Milenio BC en 
equipo viene desarrollando desde hace unos años en diferentes yacimientos de las cuencas sedimentarias de la Región de Madrid, y que han sido posibles gracias a la colaboración con las empresas y directores de las respectivas excavaciones ${ }^{2}$ o a Instituciones como la Real Academia de la Historia y el Museo Arqueológico Regional de Madrid (MAR).

Aunque todavía en fase de recopilación y de estudio, el escaso centenar de individuos (88) hasta la fecha estudiados, ha permitido obtener una amplia y variada información sobre aspectos físicos y culturales de estas comunidades del III milenio AC. (Liesau et alii, 2008; Blasco et alii, 2009; Vega et alii, 2010; Gómez et alii, 2011; Blasco y Ríos, 2011).

En este trabajo se discuten y se abordan aquellas lesiones traumáticas que pueden estar relacionadas con actos violentos y posibles agresiones en el marco cronocultural en el que se encuadran. Los contextos relacionados con el tema que nos ocupa son básicamente cuatro tumbas, dos de Camino de las Yeseras, una de Humanejos y un cráneo procedente de la necrópolis epónima de Ciempozuelos perteneciente a la colección del Gabinete de Antigüedades de la Real Academia de la Historia. A ello se suma la existencia en Camino de las Yeseras de un taller de puntas de flechas, a los que cabría añadir las panoplias de armas documentadas en algunas de las tumbas de Humanejos.

Aunque se trata de manifestaciones muy variadas que proporcionan un grado de información y documentación desigual, no deja de ser complementaria a la vez que apuntan a actos violentos de diferente naturaleza y con distintos artefactos, pues es lógico pensar que estas agresiones se deben a múltiples causas y circunstancias. En general, los actos violentos se encuadran en dos grandes grupos: Los enfrentamientos a distancia en los que, a menudo, debieron de participar varios individuos y el cuerpo a cuerpo. Ambos están representados en los casos que estudiamos.

\section{INDICIOS DE VIOLENCIA EN EL REGISTRO ANTROPOLÓGICO: LESIONES TRAU- MÁTICAS}

En Camino de las Yeseras los datos más significativos relacionados con el tema que nos ocupa se encuentran en un enterramiento múltiple no campaniforme y en un hipogeo profanado con restos muy parciales de hasta tres individuos asociados a vajilla campaniforme. De la Cuesta de la Reina de Ciempozuelos procede un cráneo trepanado también asociado a cerámica campaniforme que pudo deber su intervención a un posible traumatismo. En Humanejos se documentó en el nivel superior de una tumba múltiple campaniforme, los restos de un individuo con la afección más evidente: un golpe inciso-contuso que le produjo una importante herida en el frontal.

\footnotetext{
la Comunidad de Madrid", ref. CCG08-UAM/HUM 4061, dirigido por C. Liesau; "Estudio documental sobre las fases de poblamiento de la comunidad de Madrid vinculado a intervenciones arqueológicas", ref. 1665/2007/00, dirigido por C. Blasco; "Patrimonio Arqueológico y Documental de la Comunidad de Madrid, PADCAM" ref. S2007/HUM-0543, dirigido por C. Blasco. Proyecto de Investigación Plan Nacional HAR 2011-28731: Las sociedades calcolíticas y su marco temporal en la región e Madrid. Una revisión a la luz de nuevos datos, dirigido por C. Liesau.

2 Agradecemos la colaboración y disponibilidad a J. Vega (Argea Consultores, S. L.) y Raúl Flores (Pagadel, S. L.).
} 
2.1. ENFRENTAMIENTOS A DisTANCIA: INHUMACIONES ASOCIADAS A LESIONES POR PUNTAS DE FLECHA (FigURAS 1 Y 2)

El primero de estos contextos es una tumba en fosa con un enterramiento múltiple de Camino de Las Yeseras en la que se inhumaron los cuerpos de, al menos, 7 individuos - un hombre y otro adulto, un juvenil y cuatro infantiles- (Blasco et alii, 2009; Gómez et alii, 2011). Desgraciadamente esta tumba estaba muy alterada por las labores agrícolas por lo que, de las 7 puntas de flecha documentadas, tan solo una se conservaba asociada a un antebrazo, seguramente clavada en los tejidos musculares (Figura 2 a y b), mientras que las seis restantes además de una punta asta de ciervo, se localizaron desplazadas entre los cuerpos y el sedimento que colmataba (Figura 2 c). En el borde de la fosa quedó más o menos intacto un lote de ajuar funerario compuesto por tres cuencos lisos, un vaso cilíndrico y siete pequeñas cuentas de caliza halladas en el interior de uno de los cuencos. La tumba parece indicar una deposición simultánea de los cuerpos o en un tiempo muy breve ya que los cuerpos aparecen superpuestos sin sedimento alguno entre ellos. Por otro lado, el perfil de edad de los inhumados invita a pensar que se trata de un grupo familiar, mientras que los datos anteriores no permiten extraer mayores conclusiones sobre las circunstancias del óbito de estos individuos, la hipótesis en torno a una muerte violenta se refuerza por el hecho de encontrar las puntas de flechas dispersas entre los esqueletos, unas puntas que tipológicamente suponen una excepción por ser romboides dentro del conjunto de proyectiles líticos recuperados en el yacimiento (Figura 7, 21, 22, 24, 25, Figura 1 y Figura 2 b, M. Roca., com. pers.). También la punta en asta de ciervo, que pasó inadvertida en un estudio preliminar del enterramiento, es la primera documentada en una tumba calcolítica de Camino de las Yeseras. Su punta y pedúnculo fracturados de antiguo indican que no se trata de un mero ajuar funerario, sino su estado se debe, muy probablemente al impacto en uno de los cuerpos allí inhumados. Si las probabilidades de que la muerte simultánea de más de tres individuos por causas naturales es prácticamente nula (Chambon

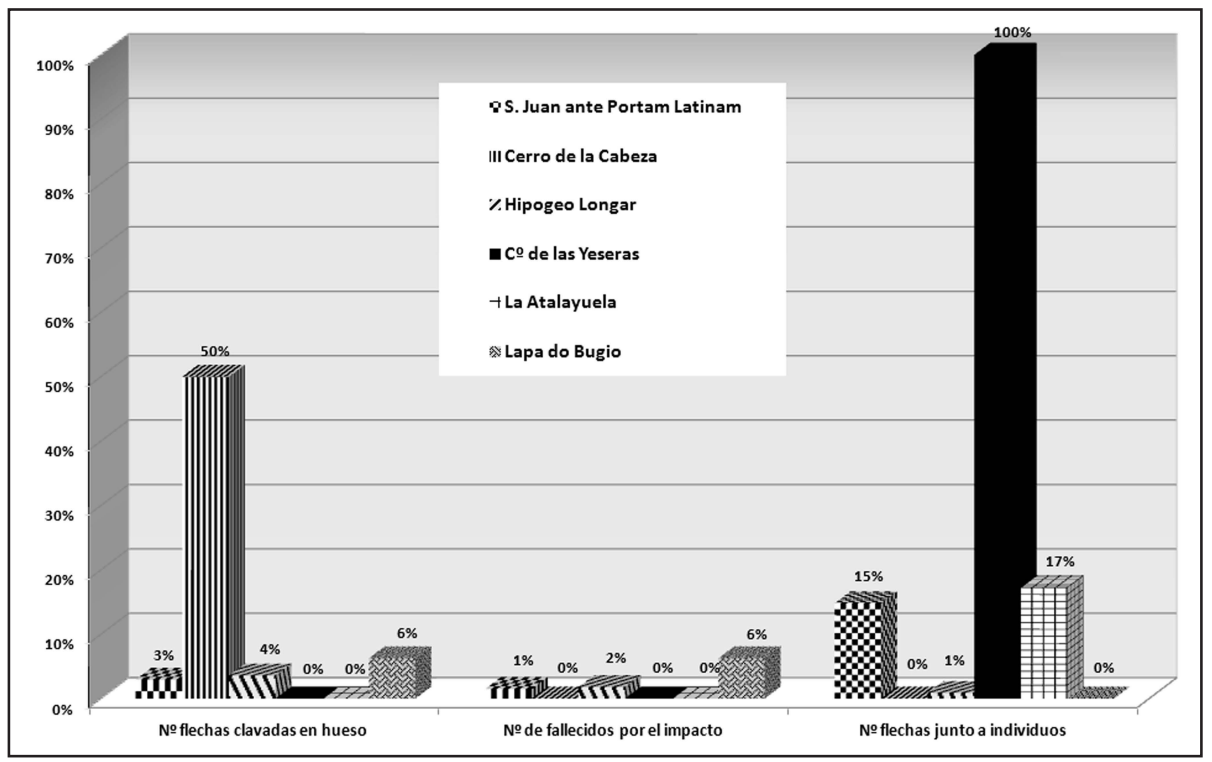

Figura 1. Comparativa en valores absolutos de las diferentes modalidades de localización de las puntas de flecha halladas en SJAPL, Cerro de la Cabeza, el Hipogeo de Longar, Camino de las Yeseras y Lapa do Bugio. 


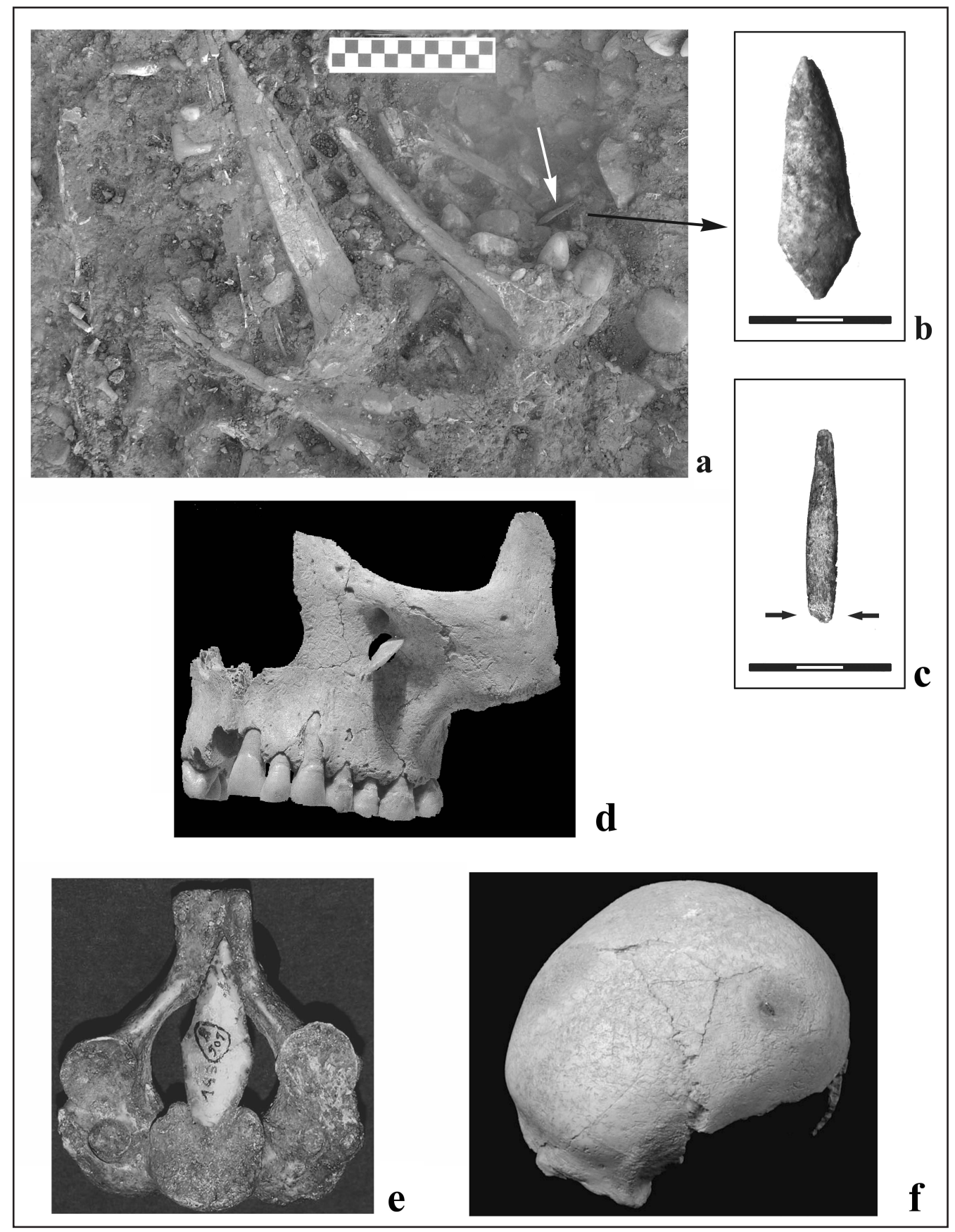

Figura 2. a.- Detalle de la posición de una de las puntas de flecha hallada junto al radio de uno de los individuos del enterramiento múltiple de Camino de las Yeseras (A01, E04) (Argea Consultores, S.L.). b.- Detalle de la punta de flecha hallada del enterramiento anterior de Camino de las Yeseras (A01, E04) (Argea Consultores, S.L.). c.- Punta de flecha en asta de ciervo con fracturas antiguas en la punta y en el pedúnculo. d.- Detalle de punta de flecha incrustada en el maxilar de un adulto del Hipogeo de Longar (Armendariz e Irigaray, 1995:26). e.- Vértebra cervical con punta de flecha clavada en el cuerpo vertebral procedente de uno de los inhumados en en Lapa do Bugio (Silva y Marques, 2010: 187, fig.2a). f.- Cráneo deCova de l'Heura, (Ulldemolins) con impacto de una punta de flecha de cobre o de bronce, normasuperolateral izquierda (Campillo, 1993: 112). 
y Leclerc, 2007: 294), la presencia de hasta siete cuerpos en esta tumba sería un argumento añadido para pensar que podemos estar ante un caso de muerte violenta colectiva.

Las lesiones por puntas de flecha son evidencias bien conocidas en contextos desde el IV milenio AC donde contamos con datos incuestionables en diferentes yacimientos. En la Figura 1 se refleja una selección de inhumaciones que se han clasificado en tres categorías según la localización de las puntas de flecha en relación con los inhumados.

Uno de los casos mejor conocidos es la tumba colectiva del Neolítico Final de San Juan ante Portam Latinam (Álava) un abrigo natural utilizado en un lapso temporal relativamente corto, datado entre 3338 y $3095 \mathrm{cal} \mathrm{AC}$, donde se inhumaron al menos 338 individuos (Vegas, 2007). Trece cuerpos de al menos 8 varones presentaban heridas por impacto de puntas de flecha (Figura 1). Pero San Juan ante Portam Latinam tampoco es el único enterramiento con puntas de flecha clavadas en los esqueletos. Una revisión de un total de 16 individuos inhumados en la cueva de Lapa do Bugio (Sesimbra) datada entre finales del IV y mediados del III milenio AC ha permitido documentar otro caso de una punta de flecha clavada en la segunda vértebra cervical de un individuo adulto (Silva y Marques, 2010) (Figura 1 y 2 e).

Otro ejemplo es el del hipogeo de Longar, con 4 varones alcanzados por puntas de flecha en brazo, maxilar (Figura 1 y 2 d), vértebra y costilla respectivamente, de los cuales sólo el último muestra cicatrización y evidencia clara de una supervivencia (Armendáriz e Irigaray, 1995). Las dataciones obtenidas fijan el momento de uso del hipogeo en un lapso comprendido entre 2950 y 2630 AC que podría ser coetáneo a la tumba de Camino de las Yeseras.

Pero sin duda alguna, el caso más próximo a la fosa de Camino de las Yeseras, por la morfología y ejecución de la tumba, por su localización en un yacimiento de "campo de hoyos", por su cronología, por tratarse de una tumba de inhumación múltiple y por su ubicación geográfica, es el Cerro de la Cabeza (Ávila) donde se exhumaron varias fosas de enterramiento con una cronología de entre 2860-2300 cal AC, que, como el hipogeo de Longar coincide con la cronología que asignamos a la tumba de Camino de las Yeseras. Una de estas tumbas en fosa contenía un enterramiento múltiple de seis individuos adultos, cinco masculinos y uno femenino. Tres de los varones y la mujer, tenían clavadas sendas puntas de flecha en distintas partes esqueléticas: brazo, entre dos costillas, la región lumbar y en el cuello (Fabián, 2006: 306-309; Fabián y Blanco, 2012: 104). Posteriormente, en la misma fosa se ejecutó la inhumación de otros dos varones, sin síntomas aparentes de heridas ni traumatismos. La diferencia más sustancial entre este enterramiento abulense y el de Camino de las Yeseras es la presencia en el yacimiento madrileño de individuos de corta edad, una circunstancia que de confirmarse el episodio violento, sería novedosa para la época

No faltan otros yacimientos como la necrópolis de Bòbila Madurell donde se recuperaron en un hoyo dos individuos masculinos con sus cráneos fracturados intencionadamente y uno de ellos presentaba además un impacto por flecha con fractura de la punta sobre una vértebra torácica (Campillo et alii, 1993). Otras evidencias de puntas de flechas clavadas se han identificado en la Cova de l'Heura y el dolmen del Collet, en el primer caso en una vértebra y en los otros dos en el cráneo (Campillo, 1993-94: 115). Uno de los cráneos tiene clavada una punta de cobre que atraviesa el hueso y sobresale $1 \mathrm{~mm}$ por la tabla interna del cráneo (Figura $2 \mathrm{f}$ ). Ésta muestra una discreta curvatura helicoidal y está rota, como consecuencia de un infructuoso intento de extracción, un impacto que no fue letal para este individuo (Campillo, 1977: 290-294).

Junto a los casos mencionados en que los proyectiles han penetrado en la estructura ósea contamos con un número mucho más alto de enterramientos en los que aparecen puntas de flecha entre los restos óseos aunque no estén clavados en ellos. Pensamos que éste sería el caso del enterramiento de Camino de las Yeseras donde los proyectiles sólo alcanzaron los tejidos 
blandos de los inhumados y se desplazaron postdeposicionalmente durante la esqueletización de los cuerpos. Ejemplos con estas características son conocidos desde hace tiempo como el de la fosa campaniforme de La Atalayuela (Agoncillo, La Rioja) que ofreció una asociación similar de puntas de flecha localizadas entre los restos humanos (Andrés y Barandiarán, 2004), conjunto interpretado en un ambiente de conflicto, como perteneciente a un grupo de "atacantes" o de alóctonos "atacados (Andrés, 1998: 97) (Figura 1). De los 161 inhumados de Can Martorell (Barcelona), tampoco se ha podido probar ningún caso de muerte a causa del impacto letal de una punta de flecha, aunque el $80 \%$ de más de medio centenar de puntas de flecha están fracturadas. En varias piezas, su estudio traceológico parece indicar que fueron empleadas como puntas de proyectil de estas (Palomo y Gibaja, 2002; Márquez et alii, 2009). Can Martorell, puede ser un ejemplo del problema que plantean los enterramientos colectivos en megalitos, en los que se producen importantes remociones y traslados de huesos que alteran la posición primaria de los esqueletos con la consiguiente pérdida de información sobre lesiones traumáticas, produciendo una aparente disminución de casos diagnosticados como víctimas de violencia en áreas de especial incidencia del megalistismo como es el SE peninsular (Jiménez-Brobeil et alii, 2009:469).

En las inhumaciones múltiples, las numerosas puntas de flechas clavadas en hueso o entre los esqueletos, y sobre todo la variedad de tipos y materias primas de las mismas que apuntan a un origen foráneo son la suma de pequeñas evidencias que refuerzan la hipótesis sobre enterramientos múltiples y colectivos por muertes violentas (Camino de las Yeseras, Cerro de la Cabeza, Can Martorell o el dolmen de Aizibita (Beguiristain, 2007; 2011).

2.2. ENFRENTAMIENTOS A CORTA DISTANCIA: INHUMACIONES ASOCIADAS A LESIONES CONTUSAS O INCISAS (Figuras 3 y 4 )

\subsubsection{Lesiones contusas}

A los indicios de lesiones causadas por impactos de puntas de flecha, fruto de enfrentamientos entre grupos o, al menos, entre varios individuos, se suman las lesiones contusas o inciso-contusas que afectan a individuos en enterramientos individuales o asociados a otros sin herida alguna. Estas lesiones contusas son menos llamativas que las anteriores y de origen muy diverso y pueden deberse a accidentes fortuitos o a enfrentamientos de corta o media distancia, por lo que pueden localizarse en cualquier parte del esqueleto. Posiblemente la mayor parte de ellas ni siquiera fueron el resultado de un acto violento, sino una consecuencia de accidentes cotidianos a los que estas comunidades estaban muy expuestas en el marco de un intenso ejercicio físico en sus actividades domésticas y laborales. La mala conservación de muchos esqueletos $\mathrm{y}$, en ocasiones, la dificultad de identificación de este tipo de lesiones puede ser alguna de las causas de haber pasado desapercibidas. A pesar de ello en un estudio recopilatorio realizado por Pérez Fernández (2010: 150) se insiste en el aumento de estas lesiones a partir del Neolítico y Calcolítico. En este sentido merece la pena destacar la evidencia de un ataque cuerpo a cuerpo documentado en el rostro de un varón de entre 55 a 65 encontrado en un hipogeo de Camino de las Yeseras que, como otras tumbas con ajuares importantes, fue saqueada en un momento no muy alejado a las inhumaciones. Afortunadamente el expolio no fue total por lo que pudimos recuperar aparte de algunos restos óseos, fragmentos de cerámica campaniforme e incluso una pequeña plaquita áurea decorada (Blasco y Ríos, 2010: Fig. $8 \mathrm{f}$ y 11). A pesar de la fragmentación del material se pudo reconstruir parcialmente la cara del individuo que presenta una fractura de los nasales a causa de un contundente golpe en la naríz 
antemortem. Aunque los nasales se soldaron otra vez en vida, reflejan una acusada desviación respecto a su trayectoria original (Figura 3).

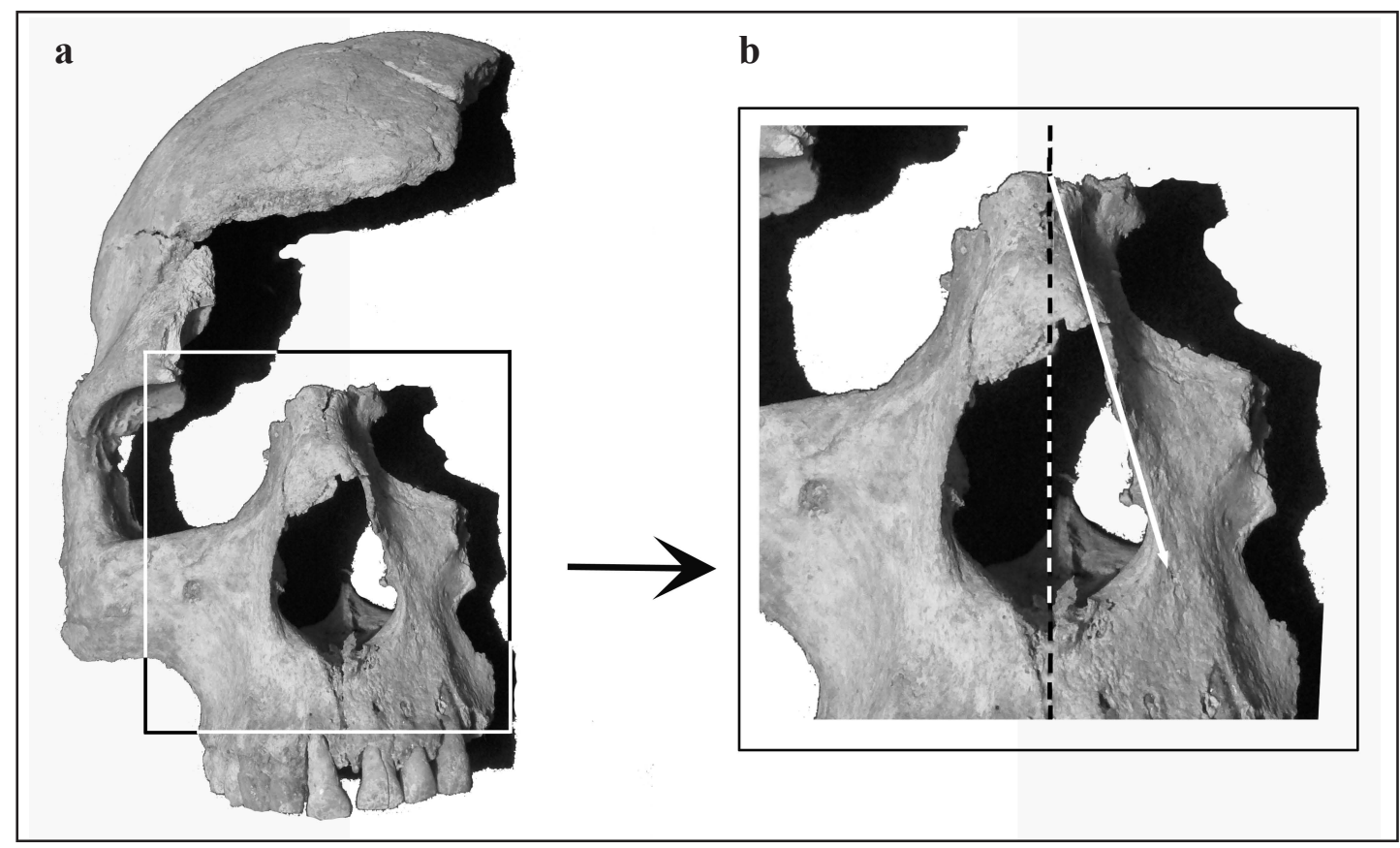

Figura 3. a. Norma frontal del cráneo de un varón senil hallado en un hipogeo campaniforme de Camino de las Yeseras (A31-01-I). b.- Detalle del trauma con fractura y desviación de tabique nasal.

Desconocemos en qué momento de la vida de este individuo se produjo el traumatismo, pero dado el tipo de lesión y la edad del hombre, pudo haber pasado bastante tiempo antes de su muerte. Las características de la tumba en la que se inhumó y el ajuar asociado permite suponer que fue un personaje con cierta relevancia social y dada su avanzada edad podríamos estar ante una manifestación que refleja un enfrentamiento selectivo dirigido a este individuo por su reconocimiento dentro de su comunidad.

Hay otros tantos casos con lesiones contusas que afectan al cráneo en los que podrían coincidir este tipo de circunstancias, como los recopilados por Jiménez-Brobeil et alii (2009) o por Pérez Fernández (2010), todos ellos fechados a partir del Neolítico. Son lesiones que afectan sobre todo a hombres adultos, algunos de ellos con supervivencia dada la regeneración parcial del tejido óseo. No descartamos que algunos de estos golpes puedan ser intencionados, como el que se observa en el frontal de un varón adulto maduro de entre 40 y 60 años inhumado en una fosa de enterramiento múltiple de el Tomillar, aunque el autor del estudio indica que generalmente se deben a "causas accidentales" (Etxeberría, 1995: 52). La edad del lesionado y su cronología ( $3780 \pm 100$ y $3830 \pm 95 \mathrm{BP})$, resultan próximas a la estimada para el individuo del hipogeo de Camino de las Yeseras, a lo que se suma que en ambos casos el golpe se produce en la cara (frontal y nasal) y ambas con resultado de fractura.

A estos ejemplos hay que sumar otro más recientemente estudiado, se trata de una lesión contusa identificada en la cabeza de un varón del yacimiento vallisoletano de Soto de Tovilla. Presenta un importante traumatismo craneal perimortem en el parietal izquierdo que, según 
sus estudiosos, fue producida "por el contacto violento de la cabeza con un elemento romo y carente de filo... de aspecto circular". La datación obtenida del individuo es de $4065 \pm 35$ BP: 2696-2487 cal AC (Esparza et alii, 2008: 21, 26).

Es probable que estos golpes propiciados en el cuerpo a cuerpo fueran los más frecuentes, en ocasiones por altercados cotidianos en los que no se utilizaban objetos y por supuesto, armas, sino que se acudía a elementos naturales como piedras o palos o simplemente a los puños. Pero tampoco hay que descartar que este tipo de golpes pudieran estar relacionados con enfrentamientos colectivos y fueran la fase final de un ataque a distancia, afectando a un individuo al azar o a un personaje concreto que, por su estatus o por su significado dentro del grupo se pretendía castigar, en cuyo caso es más probable que se hiciera uso de objetos contundentes y especialmente efectivos.

\subsubsection{Lesiones incisas o inciso-contusas}

Un tercer tipo de lesiones más probables y seguramente más letales que los de la categoría anterior son las de tipo inciso o inciso-contusas, como resultado de enfrentamientos cuerpo a cuerpo, debido a que en estos casos la lesión se debe al empleo de un objeto con filo, es decir, un útil cortante más o menos pesado, que suele dejar una clara evidencia en los tejidos óseos.

En este apartado tenemos que incluir el traumatismo más destacable en el reciente estudio realizado a un individuo de los inhumados en una de una de las tumbas del yacimiento de Humanejos (Gómez et alii, 2011:129). La tumba inicialmente se abrió para acoger en su base a otros tres individuos, de los que se ha obtenido una datación de $3825 \pm 37$ BP con una calibración a $2 \sigma$ en un intervalo $2460-2190$ cal AC. Se trata de enterramientos primarios: un varón adulto de unos 25 años, un juvenil de unos 17 a 21 años y un infantil de alrededor de 12 años dotados de un importante ajuar campaniforme. Sus cuerpos se esqueletizaron en un espacio colmatado. En un nivel superior se localizaron otros dos enterramientos primarios de varones adultos jóvenes, de constitución bastante robusta, de entre 20-25 años el primero y algo menos de 30 años el segundo. Los restos de este último, víctima de la lesión que comentamos, han proporcionado una datación de $3781 \pm 36 \mathrm{BP}$ con una con una calibración a $2 \sigma$ de $2340-2120$ cal AC. Por tanto, su depósito es poco posterior al de los cuerpos del nivel inferior o, incluso, prácticamente simultáneo. De momento no resulta posible determinar si existió algún tipo de vinculación parental entre los tres individuos inhumados en la base de la fosa y los restos documentados en el nivel superior. ¿Por qué se utilizó una tumba preexistente? ¿Fue la muerte inesperada de uno de ellos, quizás el herido, o de ambos, la que propició esta reutilización? ¿Existía algún lazo familiar? Lo cierto es que, el depósito de los cuerpos del nivel superior no se realiza con tanto cuidado como el de las primeras inhumaciones, ni el ajuar que se les otorga presenta la riqueza que encontramos asociado a los individuos depositados en la base.

Como se observa en la Figura $4 \mathrm{a}$, la herida se manifiesta en un orificio que tiene forma de 8 y sus dimensiones son: Longitud máxima: 41,63 $\mathrm{mm}$ y 28,23 $\mathrm{mm}$ en el interior. Anchura máxima: $33,45 \mathrm{~mm}$, y entre 17,72 y 12,78 $\mathrm{mm}$ en el interior. Esta lesión fue causada por un elemento cortante que seccionó el margen superior de la cortical del frontal izquierdo. Posteriormente se efectuó un apalancamiento sobre el margen inferior de la lesión con el fin de recuperar el arma que debió de quedar atrapada en el hueso frontal a causa de la pérdida de la energía cinética del golpe. Esta doble acción, a juzgar por la zona afectada, fue realizada muy probablemente por un diestro ya que la lesión afecta a parte del arco superciliar y seno del frontal izquierdo. 
Nos inclinamos por proponer que el golpe cortante se produjo con un instrumento con filo transversal, pues las características de la herida descartan tanto un útil apuntado, como un filo

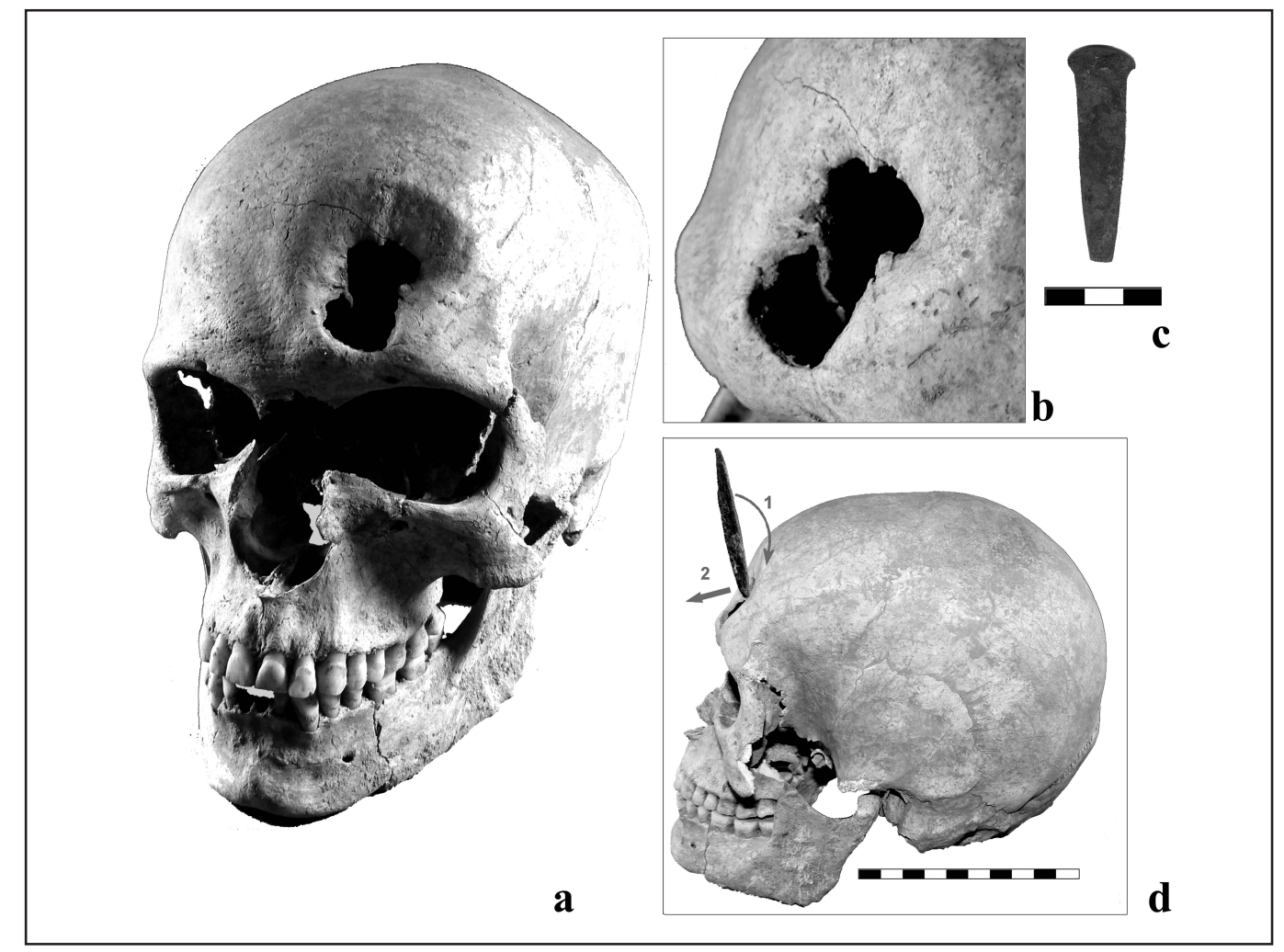

Figura 4. Vista anterior del cráneo de un varón recuperado en una fosa campaniforme de Humanejos (UE 4552) en el que se aprecia el traumatismo en el frontal izquierdo. b.- Detalle del área afectada en la que se puede diferenciar entre el borde superior biselado como resultado del impacto de un útil contundente y con filo, mientras que el margen inferior de la lesión presenta un borde irregular sin regeneración ósea, consecuencia dela avulsión de un fragmento del frontal por apalancamiento. c. Hachuela de cobre hallada en el yacimiento de Humanejos (Rovira et alii, 2011: tabla 5).

de piedra pulimentada que habría producido una lesión obtusa y no una sección limpia. Por lo tanto, lo más plausible en este caso sería el empleo de un objeto metálico de cierto peso, un instrumento semejante a una pequeña hacha o azuela de filo recto o curvo capaz de seccionar la cortical. Por la trayectoria del golpe y la fuerza de la percusión, la consecuencia natural es un movimiento hacia atrás del individuo agredido y otro de tracción opuesta del agresor. Todo ello provoca un apalancamiento que concluye con la avulsión del fragmento de frontal percutido y la liberación del arma agresora (Figura 4 d).

Aunque no muy frecuentes, estas hachitas y azuelas aparecen en contextos calcolíticos, de hecho, en el propio yacimiento de Humanejos y en el cercano de Camino de las Yeseras se recuperaron respectivamente una hachita y una azuela de cobre en contextos calcolíticos. Ambas son de características similares a las descritas para el posible objeto utilizado como arma y con un tamaño compatible con el de esta lesión aunque ninguna de ellas ha sido recuperada en un contexto funerario (Figura 4 c). La hachita localizada en la UE1361 del propio yacimiento de 
Humanejos (Rovira et alii, 2011: 300) pesa algo más que 107 gramos y mide 96 por 30 milímetros, con una anchura máxima de filo de 33 milímetros. Todo lo expuesto descarta que en el ataque descrito se usara un arma blanca apuntada como es el puñal de lengüeta al ser una pieza excesivamente liviana y poco eficaz para las acciones de percusión, aunque un arma frecuente en los enterramientos campaniformes y presente en el ajuar de uno de los inhumados del nivel inferior en la fosa en la que se enterró al propio lesionado.

La agresión antemortem no supuso la muerte inmediata de la víctima al poder apreciar con claridad una regeneración ósea (Figura 4 b). Según consulta médica (Dr. Martínez- Iñiguez, com. pers.), el tiempo de supervivencia podría ser, como mínimo, de entre dos y cuatro meses sin que sea posible determinar la supervivencia real, pues en heridas de este tamaño es normal que se detenga el proceso de osificación y no se llegue nunca a cerrar la lesión de forma completa. Más información se dispone para las trepanaciones donde Campillo (1992) afirma que el crecimiento óseo de en torno a $1 \mathrm{~cm}$ revela una supervivencia de más de un año. Otros autores defienden que esta regeneración ósea puede producirse en un plazo de entorno a unos tres meses (Fernández Díaz, 2000). Lo que sí es evidente es que, a consecuencia del apalancamiento sobre el borde o margen inferior de la lesión, no se produjo ningún proceso de regeneración en esa zona (Figura $4 \mathrm{~b}$ ).

El intento de apalancamiento de las armas ofensivas atrapadas en los restos óseos está bien documentado en el caso de las puntas de flecha en uno de los heridos del hipogeo de Longar o de Can Martorell y, posiblemente también en dos de las puntas de la fosa de Cerro de la Cabeza, donde presentan la rotura del pedúnculo. Sin duda, las armas, incluso las líticas, eran lo suficientemente importantes y apreciadas como para intentar su recuperación, siendo la extracción a veces muy complicada por acelerar el desangramiento del individuo cuando afecta a vasos sanguíneos. Menos documentada está la doble acción de incisión más apalancamiento, que Campillo lo atribuye en el caso del frontal de un cráneo recuperado en la Cueva de Xaragais (L'Espluga de Francolí) a una trepanación poco habitual y además póstuma (Campillo, 1993-94: 61, Figura 1, tomo 2; 2007: 199). Sin embargo esta acción tiene más lógica en nuestro caso, ya que la lesión del individuo de Humanejos parece deberse al impacto de un arma con filo más o menos aguzado y no a una praxis terapéutica, pues el frontal izquierdo no es una zona adecuada para dicha intervención y en cambio sí suele ser una de las partes más expuestas ante una agresión cuerpo a cuerpo (Jimenez-Brobeil et alii, 2009:472).

Un caso muy próximo al de Humanejos es el hallazgo de un cráneo procedente del dolmen de Aizibita (Cirauqui) con una fecha del 4490 50 BP (3350-2970 cal AC) (Beguiristain, 2007; Beguiristain et alii, 2010). Se trata de un adulto joven que presenta una gran lesión justamente en el lado opuesto del cráneo de Humanejos, es decir, en la región parieto-occipital causada por un arma de hoja plana cortante que incidió tangencialmente sobre la parte posterior del cráneo. Esta acción provocó un seccionado y una fractura con arrancamiento de una importante porción ósea (Figura 5b). Los autores proponen que el objeto de la agresión tuvo que ser un hacha pulimentada de filo muy cortante o un hacha plana de cobre (Figura 5 c y d) (Beguiristain y Etxeberría, 1994), aunque el Dr. Campillo discute si pudo tratarse de una trepanación (Beguiristain, 2007:72). Nos encontramos también ante una lesión antemorten ya que el individuo sobrevivió al acto de agresión como lo demuestra la cicatrización en el borde del orificio (Figura 5 b).

Otro caso más complejo de encuadrar en esta categoría, es uno de los cuatro cráneos recuperados de la necrópolis de Ciempozuelos, excavada por la Real Academia de la Historia en 1894/5 (Riaño et alii 1894). El estudio antropológico fue encargado a Antón y Ferrándiz (1897) y posteriormente revisado por el Dr. Deselaers (1917). En trabajos recientes no se descarta que, tras una lesión traumática, se practicara una trepanación en uno de los cráneos de un 
varón maduro, y que posiblemente sea un depósito secundario rodeado por un lote de piezas campaniformes cerámicas y metálicas descritas en su día por Riaño et alii, 1894:437 (Sampedro y Liesau, 1998; Liesau y Pastor, 2003) (Figura 5a). Evidentemente, resulta complicado relacionar las trepanaciones con actos terapéuticos, cuando a lo largo de la Prehistoria se co-

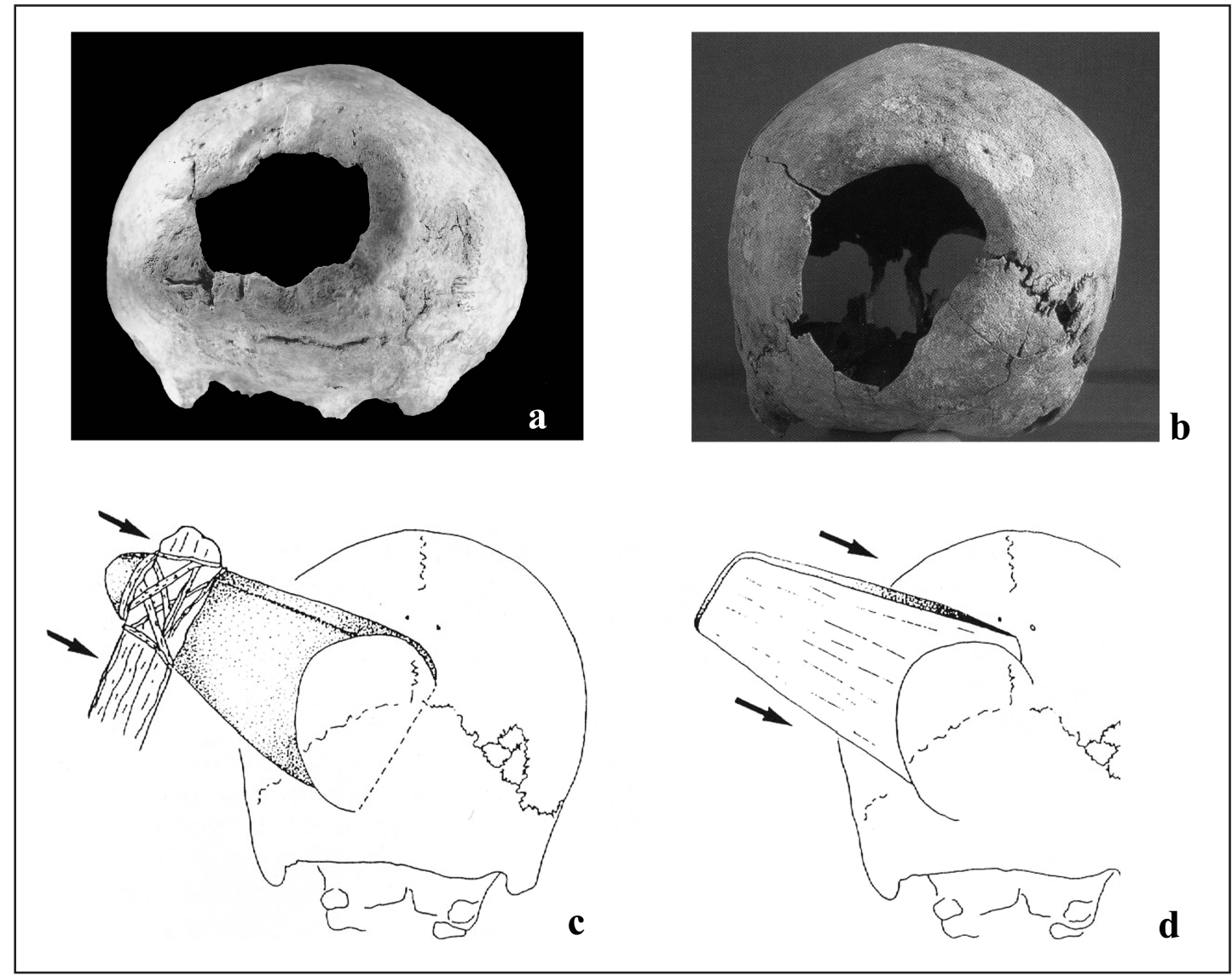

Figura 5. a.- Cráneo de la necrópolis de Ciempozuelos custodiado por la RAH con trepanación poligonal incisa realizada sobre el parietal izquierdo, vista superior-lateral (Liesau y Pastor, 2003, fig.1). b.- Cráneo del dolmen de Aizibita, con una lesión en la región parieto-occipital por la incidencia de un arma corto-contundente causando una fractura por lascado, vista posterior, según Beguiristain et alii, 2010: foto 5. c.- Detalle de algunas de las reconstrucciones propuestas: Percusión tangencial de un hacha de piedra pulimentada y otra de cobre sobre sobre el cráneo con eliminación de sustancia ósea en el impacto, según Beriguistain y Etxeberría (1994, Figura 6).

nocen numerosas intervenciones en las que se han barajado finalidades muy variadas (Guilaine y Zammit, 2002: 160-163). Sin embargo, aun siendo infrecuentes las trepanaciones realizadas en el horizonte campaniforme, no podemos descartar que alguna de ellas estuviera también vinculada a lesiones producidas por acciones violentas, sobre todo si tenemos en cuenta que los casos de trepanaciones se multiplican a lo largo del Calcolítico y especialmente durante la Edad del Bronce (Campillo, 2007), coincidiendo con el momento en que también se aumenta el registro de las lesiones traumáticas en general. 
No deja de haber también casos enigmáticos, pero poco conocidos como el del foso de Los Cercados en Mucientes, donde fueron recuperados tres cráneos de mujeres golpeadas con armas punzantes en un registro con cerámica simbólica y miles de restos de fauna, conjunto interpretado como el de una violencia sacralizada que revela una dramática subordinación de la mujer (Esparza et alii, 2008: 41; Delibes 2011:45).

Por último, y aunque no las hemos encontrado en la muestra que hemos estudiado hay evidencias de lesiones inciso/cortantes entre las documentadas en enterramientos del interior peninsular pertenecientes a un momento ligeramente posterior, ya dentro del II milenio AC. Destacamos el caso de la Motilla del Azuer, donde se han identificado en los restos esqueléticos de un individuo joven, múltiples heridas producidas por distintos tipos de armas manejadas desde diferentes direcciones, incluso ataques por la espalda, circunstancias que permiten proponer a los investigadores que podría tratarse de un ataque intergrupal con ensañamiento. Tampoco le faltan otras heridas provocadas por gestos defensivos de la víctima, datada en un $3591 \pm 37$ BP, con una calibración de 2040-1870 AC cal AC (Nájera et alii, 2010: 385-387). Como en nuestro caso de estudio estas lesiones se han producido por ataques de cuerpo a cuerpo, con armas cortantes, puñales, hachas o azuelas, etc. pero se trata de un período en el que la metalurgia y, en especial las armas blancas y otros útiles de filo cortante son muy frecuentes en los equipos materiales domésticos y funerarios.

Concluimos el apartado destacando que estos traumatismos, aunque aparentemente más llamativos que los contusos o inciso/contusos, la información que proporcionan no resulta en general tan evidente como los producidos por los impactos de proyectil. El arma agresora es recuperada y no es depositada en la tumba. En el caso de supervivencia, el recrecimiento óseo ni siquiera permite precisar el tipo de pieza empleada y los estudios se limitan a ofrecer hipótesis de las circunstancias de la agresión. Sólo en casos de traumas tan espectaculares como el que aquí nos ocupa, son claramente identificables.

\section{3. ¿SOLO CONFLICTOS O EPISODIOS DE GUERRA?: EVIDENCIAS ARQUEOLÓGICAS}

Los nuevos casos de violencia anteriormente expuestos se encuadran en el debate sobre el grado de conflicto en las sociedades prehistóricas calcolíticas que ha sido uno de los aspectos más discutidos en los últimos años (Guilaine y Zammit, 2002; Thorpe, 2005), en ocasiones haciendo referencia al tipo de organización social y otras veces teniendo como argumento la propia evidencia arqueológica, aunque muy problemática por la desaparición del registro orgánico (Vencl, 1984) y la multifuncionalidad de muchos artefactos (Chapman, 1999; Thorpe, 2005). Dada la relativa escasez de restos antropológicos que muestran signos de violencia en el ámbito peninsular, la mayor parte del debate se ha centrado en aspectos indirectos que, como ya apuntaron en su día Delibes y Pardo (1997: 85) podría ser el incremento poblacional: "un espectacular crecimiento demográfico obligó a los humanos... a modificar su secular comportamiento y a buscar nuevas alternativas culturales". Otros autores suman a esto el sedentarismo como factor esencial en el surgimiento de la violencia y el conflicto (Etxeberría y Vegas 1988; Díaz-Andreu 1995; Monks 1999; Vencl 1984; Haas 1999). En zonas bien estudiadas del sur peninsular ambos factores se relacionan además con un aumento del número de poblados, los de mayor extensión considerados como centrales y con la construcción de sistemas defensivos complejos que evidencian — según estos - una jerarquización del poblamiento. Todo ello desembocó en una notoria complejidad social, una reorganización no sin ciertas contradicciones entre las que nos interesa destacar la generalización de la violencia como consecuencia de la competencia por las mejores tierras o el logro de determinadas materias y objetos exóticos de 
difícil acceso, aspectos que para la mayoría se manifiestan tanto en el patrón de asentamientos, como en los sistemas defensivos - murallas, torres, bastiones, fosos- como en el ámbito funerario (Sangmeister y Schubart 1981; Delibes et al. 1996; Monks, 1999; Kunst 2000; Arnold y Kunst, 2011).

Para otros, los indicios de violencia o de enfrentamientos tradicionalmente considerados como la jerarquización del territorio a partir de la coerción y los sistemas defensivos de tipo Los Millares, no serían criterios suficientemente sólidos para hablar de crecimiento del conflicto y desigualdad social. En este sentido aspectos como la planificación y la inversión de trabajo han sido cuestionados como reflejo de un trabajo organizado y colectivo, propio de una sociedad más compleja y jerarquizada (Díaz-del- Río 2006, 2008). Por su tardía cronología, también ha sido cuestionada la finalidad de los fortines en Los Millares con el objetivo de controlar la población y el ganado como parte de la emergencia de una sociedad estatal (Chapman, 2008: 205). Entre los potenciales artefactos de conflicto tampoco faltan aquellas categorías de objetos con un uso, tanto de herramienta como de arma, cuya importancia como indicadores de violencia ha sido discutida dada su frecuencia en los ajuares funerarios (Chapman 1999: 108).

Todas estas propuestas tenían su correspondencia con los datos arqueológicos conocidos en contextos calcolíticos del sur y el oeste peninsular quedando al margen otras regiones, particularmente las tierras del interior. Sin embargo, las recientes excavaciones de grandes sitios con enterramientos jerarquizados, algunos de ellos con valiosos ajuares hechos con materias primas exóticas y en ocasiones acompañados con importantes panoplias de armas, han hecho cambiar la visión de escasa entidad y desarrollo de estas tierras. La cada vez mayor presencia de los recintos de fosos delimitando sitios de mayor o menor extensión nos permiten incorporar a estas comunidades en un proceso similar de inicio de la complejidad y conflictividad social que las tradicionalmente conocidas áreas periféricas.

Si tenemos en cuenta que son numerosos los yacimientos intervenidos recientemente en los que se ha podido documentar la convivencia de campaniformes y no campaniformes con una visión desde la perspectiva de la Arqueología de la Muerte muy diferente de la organización social hasta ahora asumida, es previsible que futuros estudios permitan verificar hasta qué punto dos visiones tan diferentes de la sociedad fueron compatibles o si su coexistencia pudo dar lugar a una situación de conflicto.

Los datos que aquí se aportan son una muestra de cómo la Península sufrió un proceso de transformación social mucho más uniforme y en este sentido también todas sus comunidades se vieron afectadas por las tensiones derivadas de la creciente desigualdad social un panorama en el que se encuadran las muestras de violencia que se estudian. Es precisamente, en estas evidencias anteriormente mencionadas en torno a las que queremos abordar y discutir una serie de aspectos como los relacionados con los poblados, además de otros registros de la cultura material que permitan reflexionar en torno al grado de violencia de algunas poblaciones calcolíticas peninsulares.

\subsection{LOS ASENTAMIENTOS CALCOLÍTICOS Y SUS ESTRUCTURAS DEFENSIVAS}

Durante el Calcolítico asistimos a un registro cada vez mejor documentado en relación asentamientos fortificados, como son San Blas, Castelo Velho, Santa Vitoria, Leçeia, Porto das Carretas, Monte do Tosco, Fraga da Pena, Monte da Ponte, Marroquíes Bajos, Cabezo Juré, Almizaraque, Las Pilas, Cerro de la Virgen, El Malagón, Cabezo del Plomo, Los Millares, Zambujal, etc. Como ya se ha indicado por otros autores, hasta la fecha ya son casi un centenar 
los documentados en el ámbito peninsular como otros tantos recintos de fosos, cuyo registro también ha aumentado espectacularmente en los últimos años (Jorge, 1994, 2003; Delibes et alii, 1996, 2009; Cardoso, 2008; Márquez y Jiménez, 2010; Ríos, 2011; Valera, 2003, 2008).

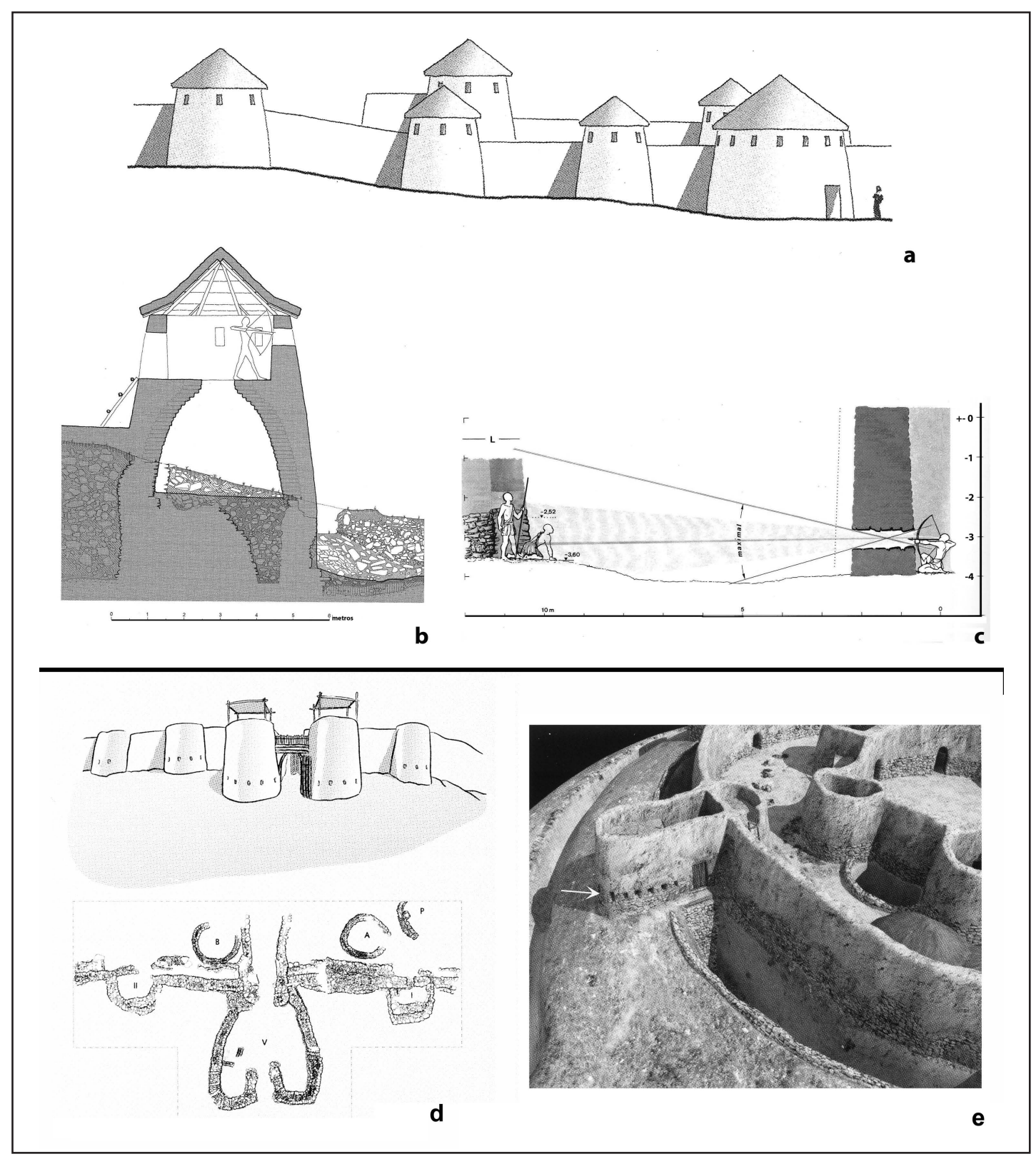

Figura 6. a: Reconstrucción de las dos líneas interiores de Zambujal en la zona KM y VX. Línea I: torres B y A. Línea II: torres K, N, L y M (Arnold y Kunst, 2011: 82 fig. 29); b: Reconstrucción de la torre B de Zambujal (Arnold y Kunst, 2011: 80 fig. 27); c: Reconstrucción del campo de tiro desde una de las aspilleras de la barbacana en relación con la entrada L de la línea II de Zambujal(Sangmeister y Schubart, 1981: 35, fig. 10a); d: Planta y reconstrucción de la puerta principal de Los Millares (Molina y Cámara, 2005: 40); e: Detalle de la reconstrucción de los sistemas defensivos del Fortín 1 de Los Millares con indicación de las aspilleras en el tramo conservado (Molina y Cámara, 2005: 66). 
Para acercarnos a las características que estas estructuras presentan, sirvan los ejemplos de Zambujal y Los Millares, tanto por su larga tradición investigadora y documentación disponible, como por presentar unas condiciones favorables de conservación de sus estructuras defensivas. En Zambujal se pudo documentar un complejo sistema de hasta cuatro líneas de murallas y bastiones además de saeteras que según fases, defienden estratégicamente diferentes entradas de difícil acceso (Sangmeister y Schubart, 1981; Kunst y Lutz, 2008). Se trata de construcciones de gran envergadura y de considerable altura según las últimas reconstrucciones (Figura 6 a y b). Ya en su día se argumentó que toda esta inversión en fuerza de trabajo sólo se podía concebir con la finalidad de protegerse ante actos ofensivos con puntas de proyectil y armas arrojadizas (Figura 6 c) (Sangmeister y Schubart, 1981: 251). También en Los Millares el esfuerzo colectivo en crear y reforzar cuatro líneas defensivas y numerosos fortines, aunque posiblemente no sincrónicos, ha sido importante a lo largo de su dilatada ocupación. Además, la documentación de barbacanas dotadas de aspilleras en sus principales accesos "pudieron servir de saeteras para disparar flechas con arco corto" (Molina y Cámara, 2005, 40) (Figura $6 \mathrm{~d}$ y e).

La manifiesta preocupación por garantizar la seguridad en el interior de las diferentes líneas defensivas en ambos yacimientos se documenta a través de continuos cambios estructurales para reforzar y rellenar tramos de murallas, pero también en la colmatación de los bastiones con la finalidad de crear una plataforma en un nivel superior, a modo de paso de ronda, para un mayor control visual y defensivo. Sin duda alguna estas modificaciones se relacionan en Zambujal con unos principios estratégicos perfeccionados con el tiempo ante reiterados conflictos de tipo bélico (Kunst, 2007: 127). Aunque estas observaciones no han sido contrastadas para otros poblados, no hacen más que reforzar la importancia de las murallas y su carácter defensivo, cuando además dataciones recientes de Zambujal han revelado una sincronía entre la cuarta línea defensiva y la primera (Kunst y Lutz, 2008), lo mismo que varios de los fortines y muy probablemente dos de las cuatro líneas de murallas de Los Millares (Molina y Cámara, 2005).

El levantamiento de grandes estructuras defensivas no permite poner en duda una planificación espacial previa, aunque sí suponer una inversión de fuerza de trabajo eventual. No obstante, la necesidad de encerrar un espacio amplio, incluso de varias hectáreas de extensión implica una inversión colectiva en fuerza de trabajo y de tiempo que no deja lugar a improvisaciones si se pretende concluir la obra y cumplir con su objetivo. Pese a que el estado de investigación presenta muchas lagunas y dificulta una visión generalizada sobre estos aspectos defensivos, no parece una tarea insignificante: desde el diseño de la trayectoria mural previa, la preparación del terreno, la coordinación del abastecimiento de toneladas de material de construcción, el levantamiento con éxito de grandes lienzos de muralla además de la elección estratégica de bastiones y el diseño de complejos accesos y saeteras. Todos estos aspectos nos acercan a considerar estas murallas y bastiones como unas normas arquitectónicas más próximas a las fortalezas del mundo antiguo que a unas construcciones prehistóricas improvisadas y levantadas a tiempo parcial con una escasa planificación previa.

Si bien es cierto que estos recintos amurallados carecen de ciertas novedades técnicas, caso del escuadrado y el uso de morteros más sofisticados, también resulta llamativo que ya durante el Calcolítico se emplearan diferentes tipos de morteros: arcilla mezclada con huesos y fragmentos de cerámica en Zambujal (Kunst y Lutz, 2008: 36), rellenos de barro con cascotes entre los dos paramentos de mampostería en Los Millares (Molina y Cámara, 2005:36), o incluso una argamasa margo-carbonatada en Leçeia donde además se insiste en una cuidadosa colocación de bloques regularizados y bien trabados entre sí (Cardoso, 2010:62). Como remate de estas estructuras pétreas los estudiosos proponen estructuras leñosas o un cuerpo 
de barro como se ha reconstruido para Zambujal y Los Millares (Figura 6 a y c) (Molina y Cámara 2005: 37; Arnold y Kunst, 2011: 82). Según los cálculos estimados, su altura podría alcanzar entre 4,5 m a $9 \mathrm{~m}$. La envergadura de estas estructuras y el esfuerzo arquitectónicos colectivo sólo se entiende desde una necesidad de garantizar la seguridad de una población, de sus bienes y de su sustento económico ante asedios violentos y prolongados en el tiempo.

Más discutible es la funcionlidad defensiva de los recintos de fosos que parecen constituirse como otra alternativa sincrónica a los recintos amurallados, y que están ampliamente representados en prácticamente toda la Península Ibérica y parte de Europa atlántica y continental. Los fosos como estructuras negativas generalmente asociadas a asentamientos denominados "campos de hoyos" aparecen en todo el ámbito peninsular con una tradición que se remonta al Neolítico y perdura aproximadamente hasta mediados del III Milenio AC. (Valera, 2003, 2008; Márquez y Jiménez, 2010; Ríos, 2011). También en el interior peninsular las excavaciones preventivas y de gran extensión han permitido documentar un importante número en los últimos años (Díaz del Río, 2003; Delibes et alii; 1996; 2006; 2009 a y b; Galindo y Sánchez, 2007; Vega et alii; 2009; Ríos, 2011), algunos de ellos, inaugurados al igual que en el SW peninsular en el Neolítico Final (García, 2013). El estudio de estos recintos es complejo, pero su construcción parece que requirió de un esfuerzo colectivo importante con el fin de servir como "espacios" en los que se desarrollaban agregaciones poblacionales frecuentes y en los que acaecía un amplio rango de actividades. Sin embargo, todavía resulta prematuro entender los mecanismos sociales de la agrupación de la mano de obra necesaria, tanto para su construcción como para su condenación (colmatación) y desmantelamiento de empalizadas y terraplenes (Márquez y Jiménez, 2010:465).

\subsection{LA PRODUCCIÓN DE PUNTAS DE FLECHA: UN ARMA COMÚN EN LOS ENFRENTAMIENTOS A DISTANCIA} DURANTE EL IV Y III MILENIO AC.

Otro argumento en favor de la existencia de conflictos violentos es la abundante presencia de puntas de flecha de sílex en numerosos yacimientos del IV y III milenio AC, y su mayor variedad tipológica a lo largo del Calcolítico. En Zambujal son frecuentes en todos los horizontes de ocupación, donde hasta la fecha se han inventariado casi un millar de piezas (Sangmeister y Schubart, 1981) (Uerpmann y Uerpmann, 2003). Su concentración junto a las construcciones defensivas es otro indicio interesante de su empleo; en Los Millares abundan junto a la muralla piezas fracturadas por impacto que son interpretadas como artefactos hallados en su contexto de uso (Aranda y Sánchez, 2005: 188).

No parece tampoco casualidad que varios lugares de producción se localicen justamente en las estructuras defensivas, entre los que destaca el denominado taller del Fortín 1 de Los Millares, especializado en la producción de las puntas de flecha, además de una vasija llena de lascas y/o preformas para la producción de puntas de flecha, recuperada en el Fortín 7 (Molina et alii, 1986; Ramos et alii, 1991; Molina y Cámara, 2005: 70-75 y 95). Así mismo, en el poblado de San Blas se localizó una acumulación de puntas de flecha junto a la puerta SW de la Torre 1 (Hurtado, 2004:146). Una relación similar apuntan las áreas de producción de puntas de flecha localizadas en la fase II del poblado metalúrgico de Cabezo Juré (Huelva), tanto en la ladera sur, como en la plataforma superior del recinto fortificado. La unidad residencial que surge en la plataforma superior a partir del segundo cuarto del III milenio AC evidencia, según sus investigadores, la presencia de un grupo social distinguido desvinculado de la producción metalúrgica - pero no de las puntas de flecha-, que se reserva el uso de los medios de defensa (fortificación) (Nocete et alii, 2004: 181, 354). De este modo, ¿podríamos pensar en la exis- 


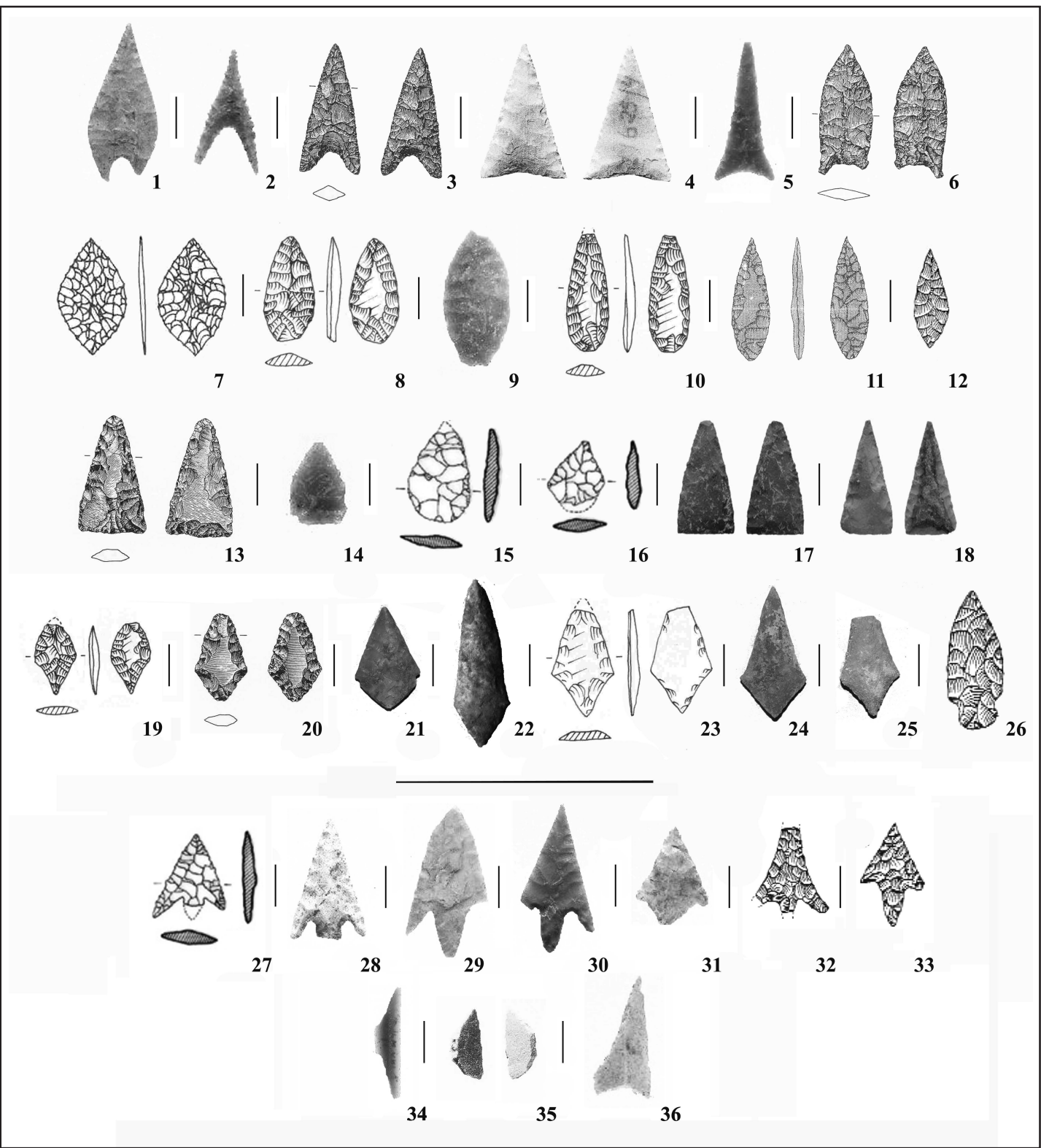

Figura 7. Tipos de puntas de flecha relacionadas con actos de violencia procedentes de varios yacimientos peninsulares: Los Millares $(1,2,5,9,14,28-31,34,36)$ (Museo de Almería online a través de Ceres-Ministerio de Educación, Cultura y Deporte), Zambujal (3, 4, 6, 13, 20, 35) (Uerpman y Uerpman, 2003: 108, Abb. IV.11-14; Taff 7: 9 y Taff. 2: 393, San Juan Ante PortamLatinam (8, 10, 19 y 23) (Vegas, 2007: 113-114, Fig.4 y 5), Longar (11) (Armendáriz e Irigaray, 1995: 24), Cerro de las Cabezas $(15,16,27)$ (Fabián, 2006: 308, fig. 147), Monte Cardim 6 $(17,18)$ (Valera et alii., e.p: fig. 4.16 y17), y Camino de las Yeseras $(21,22,24,25)$ (Argea Consultores, S. L.).

tencia de arqueros especializados? Y, por otro lado, la situación estratégica y la fortificación del espacio central en el caso de Cabezo Juré donde se concentraba, primero, el almacenaje de la comunidad y después ese grupo social distinguido, ¿puede interpretarse como evidencia de una situación de inseguridad? 
También en Camino de las Yeseras hemos podido documentar un área especializada en la producción de puntas, localizada cerca de la zona central del poblado, seguramente la más protegida por estar al interior de los recintos de foso, aunque el carácter defensivo del sitio no sea evidente ni por su posición ni por la presencia de construcciones de envergadura (Ríos, 2011: 500-509).

Otro aspecto en el que queremos incidir es en las características tecnológicas de aquellas puntas de flecha interpretadas como armas. En general, resulta interesante destacar que la mayoría de ellas representan una ejecución poco depurada. Abundan piezas que se reducen a simples esbozos de punta y/o elementos más o menos apuntados sin una reducción bifacial compleja, sino aprovechando morfologías apuntadas y filos. Tampoco los tamaños y, mucho menos los tipos, son homogéneos o estandarizados, ni siquiera en los proyectiles que aparecen en una misma muralla o en un mismo enterramiento (Figura 7).

En una somera revisión del registro de puntas en diferentes yacimientos podemos observar cómo la mayor parte de las que se pueden vincular con actos violentos - murallas, enterramientos - son de tipo foliáceas, lanceoladas y romboidales. Se documentan en Zambujal, Millares, Longar, dolmen de Aizibita, Camino de las Yeseras, San Juan Ante Portam Latinam, Lapa do Bugio, La Atalayuela o Cerro de las Cabezas, entre otros. A veces, también presentan la base configurada - hendida, cóncava, adelgazada - para mejorar el enmangue (Figura 7, 1-26).

En el caso de las romboidales se realizan con frecuencia pequeños pedúnculos y escotaduras laterales que también estarían encaminadas a mejorar la inserción en el vástago aunque no tengan el pedúnculo configurado. Junto a estas, son habituales las puntas de morfología triangular, de base recta o curva (Figura 7, 13-18). También aparecen las típicas puntas de pedúnculo y aletas, muy frecuentes en otros contextos (domésticos o como ajuar funerario), pero entre las que destaca su gran variabilidad en Los Millares, Can Martorell, Cerro de las Cabezas o La Atalayuela (Figura 7, 27-33).

Otros tipos que parecen tener una menor presencia son las puntas tipo Clovis con pedúnculos laterales, presentes por ejemplo en Zambujal y en Lapa do Bugio (Figura 7, 6). Los microlitos y otros apuntados geométricos presentan un claro descenso frente a la etapa neolítica (Figura 7, 34-36). Todos estos tipos presentan tamaños variables que oscilan en longitud desde poco más de $1 \mathrm{~cm}$ hasta $5 \mathrm{~cm}$, y en anchura desde $1 \mathrm{~cm}$ a $3 \mathrm{~cm}$ aproximadamente, sin que exista un módulo característico.

La frecuencia de las morfologías alargadas estaría sin duda en relación con una buena capacidad de penetración dada su longitud respecto a su anchura, tal y como evidencian algunos trabajos experimentales realizados en pieles gruesas, tejidos blandos y también en hueso de caza mayor (bisontes, cérvidos y suidos (jabalíes y porcino). Sus bordes cortantes en ambos filos les añaden una mayor eficiencia y una clara superioridad en su capacidad de penetración frente a las puntas de proyectil realizadas en asta o hueso (Stodiek y Paulsen, 1996:34, Sudhues, 2004: 91).

Una cuestión que nos parece clave a destacar es que muchas de las piezas anteriormente comentadas, de haber sido halladas en otros contextos, p.ej. domésticos, entenderíamos que son meras "preformas" de puntas de flecha a falta de inscribir en ellas pedúnculos, aletas, etc. Estas observaciones vienen a confirmar que pese a la existencia de especialistas que producirían piezas de forma más o menos estandarizadas y elaboradas evidenciada por ej. en el taller de Camino de las Yeseras, para los proyectiles usados en los enfrentamientos servían también puntas menos configuradas, siempre que tuvieran la capacidad de penetrar independientemente del tipo de enmangue. Quizá, en momentos de necesidad cualquier habitante pudo tallar su 
punta de flecha - tal y como sucedería con otros útiles domésticos ${ }^{3}$ (Blasco et alii, 2007: 157) - sin despreciar como arma cualquier otro objeto de naturaleza orgánica o inorgánica (Vencl, 1984: 126). En el caso de las puntas, un conflicto imprevisto provocaría la utilización masiva de piezas sin terminar acumuladas en los talleres de los especialistas, tal y como demuestran Los Millares, Cabezo Juré y Camino de las Yeseras.

Otro excelente argumento a favor del empleo de piezas improvisadas es el ejemplo de la famosa momia calcolítica de los hielos, Ötzi, un varón adulto hallado en los Alpes italianos que portaba dos puntas de flecha enmangadas, un arco y otras flechas a medio hacer, junto al equipo necesario para este proceso de fabricación además de su indumentaria especializada de alta montaña (Spindler, 1995). Este excepcional hallazgo ha sido objeto de un sinfín de estudios científicos, entre los que nos interesa destacar el de una punta de flecha alojada en su cavidad torácica izquierda. A pesar del minucioso estudio al que ha sido sometida la momia desde su descubrimiento, los estudiosos tardaron diez años en conocer, al menos, una de las causas de su muerte violenta: el impacto de una tosca punta de flecha con una punta redondeada y pedúnculo que revela un escaso grado de elaboración. La pieza tiene tan sólo $2 \mathrm{~cm}$ de longitud y penetró en la víctima por la espalda causándole un shock hemorrágico (Gostner y Egartner Vigl, 2002; Pertner et alii, 2007). No menos interesante resultan los estudios de restos de sangre analizados de las puntas de flecha enmangadas que acompañan a la víctima, una de ellas ha revelado sangre de dos individuos, es decir, después de asaetear a dos personas con la misma flecha, extrajo su valiosa arma sin que se saliera la punta del vástago, mientras que a él le ocurrió lo contrario; tras el flechazo él u otro individuo intentó extraerla sin éxito. Esta segunda circunstancia parece que fue habitual según se desprende de numerosas piezas documentadas en el interior de cuerpos inhumados, algunas con el pedúnculo fracturado por el impacto o durante el intento de extracción. Trabajos experimentales advierten además que, según el ángulo de impacto del proyectil, las huellas documentadas pueden ser confundidas con huellas de descarnado (Smith et alii, 2007). Las condiciones de conservación excepcionales de esta momia y la circunstancia de su muerte puede confirmar tres aspectos importantes en relación con las puntas de flecha calcolíticas que nos ocupan: la alta estima de las piezas de proyectil, habitualmente recuperadas tras su impacto, los no menos valiosos vástagos $\mathrm{y}$, por último, destacar los diferentes tipos de enmangues de los adhesivos — brea de abedul o resinas — realizados en los asentamientos. Parece que en más de una ocasión, la premura en su uso no permitía una fijación adecuada para su posterior extracción.

\subsection{LA PRODUCCIÓN DE PUNTAS DE FLECHA: ¿PIEZAS ClAVE PARA JUSTIFICAR UNA MAYOR ACTIVIDAD CINEGÉTICA?}

También se ha barajado que la producción de las puntas de flecha podría estar en función de las actividades cinegéticas (Nocete et alii, 2004: 354). Para justificar una mayor producción de puntas con esta finalidad, el registro material tendría que verse consolidado con una considerable variedad y mayor número de puntas de proyectil, aspecto que a grandes rasgos parece cumplirse. Cabe pensar entonces, en función de la talla de las presas, en la necesidad de producción de una amplia gama de puntas y jabalinas, tanto para acortar distancias con la finalidad de herir o abatir la caza mayor, como también para la caza de aves, independientemente de las estrategias empleadas: la espera, el rececho, las batidas con perros, y en los que no nece-

\footnotetext{
3 Entre la industria de carácter doméstico, frecuente en contextos habitacionales, es habitual la presencia de lascas y láminas sin configuración encaminadas al uso del filo cortante que suelen presentar retoque mecánico seguramente generado por este uso doméstico (Blasco et al., 2007: 157).
} 
sariamente tienen que intervenir sofisticados proyectiles para su abatimiento. Evidentemente, también en este caso la desaparición del material orgánico en el registro arqueológico no juega a favor de una interpretación más fiable de los contextos, sin embargo si lo hacen los restos de fauna identificados como desechos alimentarios.

¿Qué datos nos aportan los estudios arqueozoológicos? Afortunadamente algunos grandes yacimientos calcolíticos disponen de estudios con un registro abundante desde el punto de vista faunístico. Sirvan de ejemplo, una vez más, Zambujal y Los Millares además de dos grandes recintos de fosos como son Valencina o Camino de las Yeseras. Las muestras de los tres primeros son cuantitativamente fiables para valorar la relación fauna doméstica y cinegética consumida, mientras que para Camino de las Yeseras, todavía en fase de estudio, puede sufrir cambios en relación con las proporciones de consumo de las dos categorías de fauna (Tabla 1, valores absolutos).

\begin{tabular}{|l|c|c|c|c|c|c|c|c|c|c|}
\hline & \multicolumn{2}{|c|}{$\begin{array}{c}\text { ZAMBUJAL } \\
\text { Driesch y } \\
\text { Boesneck,1976 }\end{array}$} & $\begin{array}{c}\text { LOS MILLARES } \\
\text { Peters y Driesch, } \\
1990\end{array}$ & \multicolumn{2}{|c|}{$\begin{array}{c}\text { LOS MILLARES } \\
\text { Navas et al., 2005 }\end{array}$} & $\begin{array}{c}\text { VALENCINA } \\
\text { Hain, 1982 ; } \\
\text { Pajuelo y López } \\
2013\end{array}$ & \multicolumn{2}{c|}{$\begin{array}{c}\text { C. DE LAS } \\
\text { YESERAS } \\
\text { Liesau, 2011 }\end{array}$} \\
\hline \%NR/\%PESO & \%NR & \%PESO & \%NR & \%PESO & $\%$ NR & $\%$ PESO & \%NR & $\%$ PESO & $\%$ NR & $\%$ PESO \\
\hline $\begin{array}{l}\text { MAMÍFEROS } \\
\text { DOMÉSTICOS }\end{array}$ & 86,5 & 87,7 & 84,3 & 85,6 & 83,9 & 86,2 & 95,4 & 93,8 & 98,2 & 95 \\
\hline $\begin{array}{l}\text { MAMÍFEROS } \\
\text { SILVESTRES }\end{array}$ & 4,8 & 11,6 & 5,8 & 13,4 & 5,3 & 13,4 & 3,2 & 6,1 & 1,0 & 5 \\
\hline CONEJO & 8,4 & 0,7 & 9,4 & 1,0 & 10,4 & 0,4 & 1,2 & 0,1 & 0,3 & - \\
\hline AVES & 0,3 & - & 0,5 & - & 0,3 & - & 0,2 & - & 0,5 & - \\
\hline TOTAL & 100 & 100 & 100 & 100 & 100 & 100 & 100 & 100 & 100 & 100 \\
\hline NR ABSOLUTOS & 81.136 & 59.643 & 13.026 & 77.590 & 10.883 & 1.845 .736 & 29.051 & 51.3410 & 1.063 & 13.221 \\
\hline
\end{tabular}

Tabla 1. Relación relativa de las categorías domésticas y silvestres de diferentes yacimientos calcolíticos en comparación con el conejo y las aves silvestres, según los parámetros relativos del NR y Peso. Zambujal, según Driesch y Boessneck 1976: Tablas 4, 6 y 7; Boessneck y Driesch, 1981. Los Millares, según Peters y Driesch, 1990, tablas 2 y 8 . Queda excluida de la cuantificación la fauna procedente de los fortines, los restos de asta de ciervo, la microfauna, las aves no determinadas y dos fragmentos de cáscaras de huevo de avestruz). La tercera columna de Los Millares resume los resultados del trabajo de Navas et alii, 2005; tablas 3 y 4 y también queda excluida la fauna de los fortines. Valencina, según los trabajos de Hain, 1982, tablas 3 y 6 y Pajuelo y López, 2012, Tabla 5.Otros estudios recientes, nose han incluido, al tratarse demuestras reducidas que no modifican los datos generales de esta tabla (Abril et alii, 2010) o siguen otros criterios de estudio que dificultan encuadrar los taxones en las categorías establecidas (Bernáldez-Sánchez et alii; 2012). Por último, Camino de las Yeseras, según Liesau, 2011, tabla 7.

Teniendo en cuenta el número de restos (NR) la fauna doméstica, con un rango de entre el $84-98 \%$, supone el principal recurso cárnico en todos los yacimientos, mientras que el aporte cinegético no es más que un complemento alimentario en una gestión ganadera basada fundamentalmente en la explotación del vacuno, los ovicaprinos y el porcino. Del aporte cinegético reflejado en la Tabla 1 se han aislado los restos del conejo, al ser generalmente un factor distorsionante en la valoración de la fauna silvestre de cualquier yacimiento. De hecho, en yacimientos como los de Los Millares o Zambujal su elevada frecuencia (8-10\%) puede deberse a muchas causas: exhaustivas técnicas de recuperación, capturas frecuentes donde las huellas de origen antrópico permitan confirmar su consumo (incisiones, combustión etc.) o 


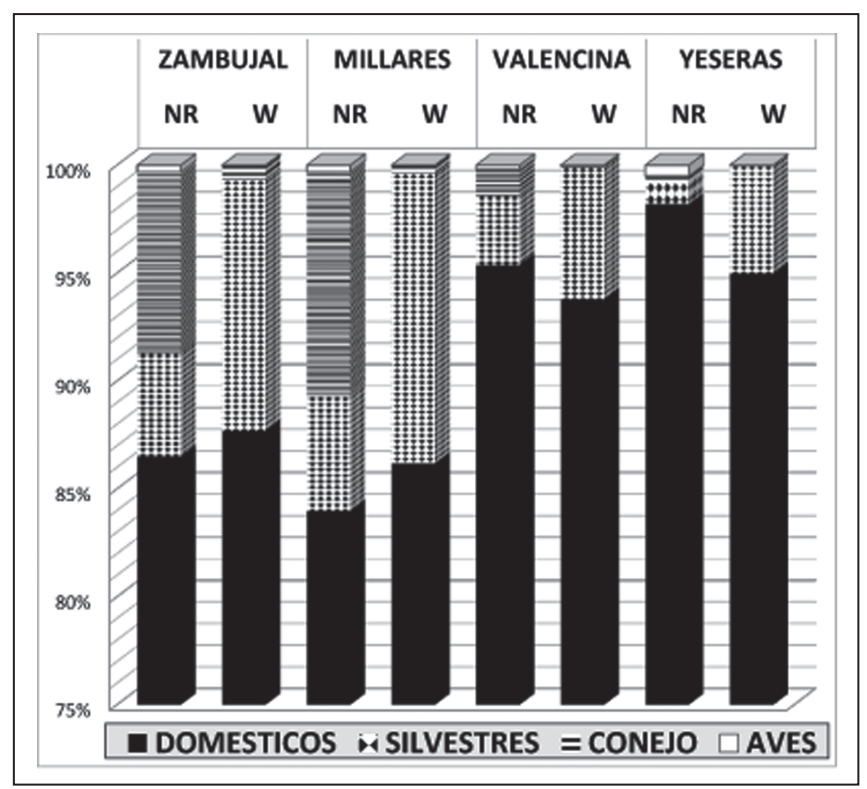

Figura 8. Detalle del histograma con los valores relativos del NR y Peso en las categorías de fauna establecidas de la Tabla 1 con desglose de los valores para los mamíferos domésticos, silvestres, conejos y aves.

problemas de intrusiones posteriores por sus hábitos fosores, etc. La avifauna, con unos valores que no superan el $0,5 \%$ en NR es también un recurso escasamente aprovechado en todos los yacimientos (Tabla 1).

Teniendo en cuenta el parámetro del peso (W), podemos destacar a los grandes ungulados domésticos y silvestres como los auténticos protagonistas en la búsqueda de un buen rendimiento cárnico. En Zambujal los datos del peso arrojan las siguientes variaciones, según las fases 1-4: caballo (1,8-1,6\%), el uro (2,7-4,9\%), el ciervo (4,9-5,7\%) o el jabalí (1-2,7\%; Driesch y Boessneck, 1976:Tabla7). Aunque se constata un gradual incremento de fauna silvestre a lo largo de sus fases, los respectivos aportes no dejan de ser anecdóticos y tampoco hay suficientes datos para especular con un aumento poblacional. Por tanto, los investigadores insisten en que la caza mayor ocupa un rango secundario desde el punto de vista paleoeconómico. Algo similar ocurre con los restos de fauna hallados entre los cuatro recintos amurallados de Los Millares, donde los aportes de la caza mayor son algo mayores porque los restos de ciervo (9\%) y del caballo (1,7\%) toman un mayor protagonismo (Peters y Driesch, 1990: Tabla 8). En Valencina, a pesar de disponer de una amplia lista de taxones cazados, los valores del peso del ciervo, uro y caballo apenas superan el 6\% del total de mamíferos (Hain, 1982, tabla 6 Pajuelo y López, 2013: tabla 5). Camino de las Yeseras presenta también valores similares, aunque por el tipo de contextos y lo reducido de la muestra, los resultados son todavía provisionales.

El criterio del peso, evidentemente por la naturaleza de las aves, no sirve para valorar su papel en el conjunto de fauna silvestre aprovechada en estos poblados, pero si cabe destacar en todos ellos la gran variedad de especies siendo algunas, comprensiblemente, recurrentes: la perdiz y diferentes anátidas. La presencia de otros taxones menos rentables o apetecibles (paseriformes, rapaces o carroñeras) es testimonial y posiblemente podrían ser excelentes proveedores de materia prima — plumas remeras y de la cola — suficientemente robustas para su engarce en los vástagos de las flechas. 
Concluimos la discusión faunística en que no se puede postular una mayor producción de talla lítica especializada con la finalidad de abatir un mayor número de taxones cinegéticamente interesantes. Los resultados de las muestras faunísticas aquí expuestas son lo suficientemente representativas como para confirmar la marginalidad y el oportunismo de la mayoría de las especies abatidas, y cuya presencia, en no pocas ocasiones, es más relevante como indicador medioambiental que de un aprovechamiento culinario rentable.

\subsection{LAS PUNTAS DE FLECHA: ELEMENTOS DE PRESTIGIO EN LOS CONTEXTOS FUNERARIOS}

Con los casos arriba descritos, parece que hay suficientes argumentos para suponer que un importante lote de producción de flechas se quedaría en reserva como parte del equipo ofensivo o defensivo empleado en los enfrentamientos intergrupales o personales, mientras que una pequeña parte podrían haber sido destinados a la actividad cinegética. Serían por tanto, herramientas comunes y multifuncionales como lo demuestra la enorme variabilidad en tipos y calidades en el registro arqueológico.

Sin embargo, el aumento de la producción a lo largo del III milenio AC de forma especializada nos lleva, por último, a considerar el otro tipo de contexto en el que aparecen, las tumbas de los "portadores" de las flechas o de arqueros.

Las puntas de flecha a partir del Neolítico Final y durante el Calcolítico empiezan a ser un elemento de ajuar recurrente en numerosas inhumaciones del ámbito peninsular (Leisner, 1943, Ayala, 1987, 1990; Chapman, 1981; Lomba et alii, 1995; Andrés y Barandiarán, 2004, Nocete, 2004; Beguiristain, 2011). Los últimos estudios para el caso de Los Millares llegan a la conclusión de que se trata de elementos de prestigio comparables a otros ya que, por un lado, sólo aparecen en cantidades considerables en unas pocas tumbas y siempre están asociados a los más ricos conjuntos de objetos exóticos y puñales en sílex. Por otro lado, los análisis de materias primas (sílex), tanto de las puntas que aparecen en las tumbas, como las del Fortín 1 confirman que no se trata de sílex local sino que proceden del intercambio interregional bien documentado en la zona con un incremento de la explotación de minas de la meseta granadina (Ramos et alii, 1991). Ambos aspectos han sido interpretados en favor de la existencia de un grupo social específico que tendría acceso a estos objetos permitiendo así el surgimiento de guerreros durante el III milenio AC (Aranda y Sánchez, 2005: 191), al igual que proliferación de grandes láminas en los contextos funerarios cuya funcionalidad se vincula a las prácticas agrícolas (Ramos et alii, 2009: 26) o ser polifuncionales, pero con un carácter ideológico en su amortización en las tumbas (Gibaja et alii, 2009:67).

Se trata de una tendencia que presenta un mayor énfasis en los ajuares de las élites campaniformes en las que por primera vez se configura una panoplia metálica en la que destacan el puñal, las puntas de palmela (y en menor medida a las silex) y otros elementos de arquero con los que los "príncipes" reafirman su rango y estatus (Fernández Manzano y Montero, 1997: 112-113). Pero no faltan autores que interpretan estos equipos como no funcionales sino simbólicos. A unas complejas y competitivas asociaciones funerarias de unos pocos y selectos personajes se les encomienda con coraje, resistencia y astucia en asumir el poder de los ancestros para proteger a los vivos del Mal y de los espíritus del otro mundo (Case, 2004:29).

\section{CONCLUSIÓN}

Con estos nuevos casos se amplía la información sobre los indicios de violencia de las poblaciones calcolíticas del interior peninsular que realizan prácticas de inhumación en centros 
grandes o pequeños articulados por recintos de foso. Las lesiones documentadas se encuentran en contextos funerarios diversos y parecen también indicar un tipo de enfrentamiento que responde a modalidades muy diferentes, aunque no podamos descartar otras variantes que, en resumen, son: agresiones cuerpo a cuerpo y ataques a distancia.

Los ataques a distancia se efectúan mediante lanzamiento de jabalinas o tiro con arco de flechas con puntas en sílex que, en casos como el que presentamos, se asocian a ejemplares con tipologías ajenas a las habitualmente halladas de Camino de las Yeseras. Otros datos que ayudan a interpretar estas tumbas en un contexto de muertes violentas son: la recuperación de puntas de flecha completas o fracturadas e incompletas entre los esqueletos, la evidencia tafonómica de la simultaneidad de las inhumaciones poco probables por causas naturales, las típicas lesiones causadas por gestos de protección y un perfil de edades indiscriminado, incluidos infantes, un sector de la población que desde luego no es responsable de la causa de conflictos. Se trata, por tanto de informaciones puntuales que advierten sobre episodios de agresiones intra o intergrupales, si bien estadísticamente son los varones adultos los más afectados.

Desde el punto de vista de las armas utilizadas, no hay duda de que en los ataques a distancia sólo tenemos datos del empleo de puntas de flecha líticas, a las que se suma las realizadas en asta de ciervo. Al estar clavadas o asociadas a los esqueletos, además de haber sido recuperadas en los lienzos de los yacimientos amurallados, su función no deja lugar a dudas, pero si dejan abierto el debate sobre el papel de la panoplia campaniforme $\mathrm{y}$, en concreto el de las numerosas puntas de cobre de tipo Palmela recuperadas en cantidad de enterramientos campaniformes, muy abundantes en la Península a diferencia de otros grupos campaniformes europeos que sólo incluyen en sus ajuares funerarios las puntas de sílex (Lemercier, 2011). Además, el uso generalizado de las puntas de sílex como armas queda reforzada por los datos que ofrecen los talleres especializados y su ubicación estratégica junto a las estructuras defensivas, que ya en el III milenio AC destacaban por su gran envergadura, sofisticados accesos e incluso alguno con pasos de ronda.

Sin embargo, hay que entender que las puntas de flecha son piezas de uso polivalente, y que durante el Calcolítico destacan por la escasa homogeneidad tecnológica frente a otras piezas estandarizadas procedentes de talleres especializados. Es probable, que esta variabilidad tipológica y tecno-funcional se deba tanto a la improvisación en su ejecución, como al reciclado o al intercambio. Pero una idea más destacable a valorar, es que en estos lotes quedan también incluidas piezas tradicionalmente consideradas "preformas" ante necesidades puntuales de ataque o de defensa, mientras que aquellas técnica y estéticamente bien elaboradas en las tumbas presentan un valor simbólico.

Otro indicio a favor de una producción de puntas de flecha o de jabalinas como elemento armamentístico queda justificada por un escaso registro de la fauna cinegética recuperada. Si bien es cierto que a fecha de hoy, no disponemos de muestreos que cubran todos los espacios y áreas "funcionales" de los mismos, los restos faunísticos como desechos alimentarios coinciden en que la ganadería de bovinos, ovicaprinos y porcino son la principal fauna consumida, mientras que las especies silvestres son un mero complemento alimentario de estas comunidades calcolíticas.

En las agresiones de cuerpo a cuerpo la refriega parece ser más selectiva y afecta también de manera mayoritaria a los varones adultos. Los ejemplos aquí presentados se dirigen a dos personajes de elevada categoría social que además han sido recuperados de grandes tumbas y con importantes ajuares campaniformes. ¿Acaso fueron individuos de estas características los más expuestos a las agresiones individuales selectivas?

Menos datos tenemos sobre los artefactos empleados en estos ataques cuerpo a cuerpo, posiblemente más variados y de empleo expeditivo, pero tampoco parece que se hiciera uso 
generalizado de las únicas armas blancas que conocemos para los momentos finales de III milenio: el puñal de lengüeta. Más bien parece que se utilizaron útiles multifuncionales como hachas o azuelas en los casos de heridas incisas. El varón campaniforme del yacimiento de Humanejos ha permitido reconstruir, no sólo la trayectoria de percusión y el acto de apalancamiento con avulsión de parte de su frontal para liberar el arma agresora, sino que además todo parece indicar un acto de percusión con una hachuela de cobre (Rovira et alii, 2011: 300). Es precisamente una pieza que no forma parte de los habituales ajuares metálicos campaniformes en el ámbito peninsular, sino que sólo aparece ocasionalmente en áreas de hábitat. La supervivencia de casos como el descrito y otro de Ciempozuelos asociado a una trepanación de la que, evidentemente no es posible averiguar la causa de la lesión, son de todas formas un tímido comienzo de la puesta en valor sobre los cuidados que recibían estos personajes para garantizar su supervivencia, cuidados que se conocen mucho mejor en sociedades de la Edad del Bronce, donde las evidencias de lesiones son frecuentes.

Todos estos aspectos nos parecen evidencias suficientes para apuntar que desde finales del Neolítico y a lo largo del Calcolítico el grado de conflictividad va en aumento, aunque muchos de los registros ofrecen una calidad de información desigual. En este sentido, prácticas de exposición de cadáveres, frente a otras pocas realizadas en fosa, han provocado una merma importante en los estudios antropológicos en general, y en las lesiones por actos de violencia en particular. A pesar de ello, todo apunta a que posiblemente sean precisamente estos actos violentos o muertes por enfermedades de rápida evolución, los que justifiquen inhumaciones múltiples en fosa durante el Calcolítico precampaniforme frente a otras pautas de exposición e inhumaciones secundarias en algunos yacimientos. De lo que no cabe duda alguna, es que los actos de violencia todavía no responden a actuaciones normalizadas y fruto de una organización más jerarquizada, sino que, en buena medida, son fruto de altercados ocasionales o mantenidos, entre grupos de dimensiones modestas.

\section{BIBLIOGRAFÍA}

Abril, D.; Nocete, F.; Riquelme, J. A.; Bayona, M. e Inácio, N. (2012): “Zooarqueología del III Milenio A.N.E. El barrio metalúrgico de Valencina de la Concepción (Sevilla)", Complutum, 2010, 21, 1, 87-100.

Andrés, T. (1998): Colectivismo funerario neo-eneolítico. Aproximación metodológica sobre datos de la Cuenca alta y media del Ebro. Zaragoza: Institución Fernando el Católico.

Andrés, T y Barandiarán, I. (2004): "La tumba calcolítica de la Atalayuela, treinta y cinco años después", Saldvie, 4, 85-124.

Antón Ferrándiz, M. (1897): “Cráneos antiguos de Ciempozuelos”, Boletín de la Real Academia de la Historia, XXX, 467-483.

Armendáriz, J. e Irigaray, S. (1995): "Violencia y muerte en la Prehistoria: El hipogeo de Longar", Revista de Arqueología, XVI, 168, 16-29.

Aufderheide, A. y Rodríguez-Martín, C. (1998): The Cambridge encyclopedia of human paleopathology. Cambridge: Cambridge University Press.

Aranda, G. y Sánchez, M. (2005): "The origins of warfare: later prehistory in southeastern Iberia". En M. Parker Pearsonm e I. J. N. Thorpe, (ed.), Warfare, Violence and Slavery in Prehistory: BAR, International Series, 1374, 181-194.

Arnold, F. y Kunst, M. (2011): “Zur Rekonstruktion kupferzeitlicher Befestigungsanlagen auf der Iberischen Halbinsel - Turm B von Zambujal (Torres Vedras, Lisboa, Portugal)". Madrider Mitteilungen, 52, 36-86 y Farbtaf. 1 y Taf. 1-12.

Ayala, M. (1987): "Enterramientos calcolíticos de la Sierra de la Tercia. Lorca. Murcia. Estudio Preliminar", Anales de Prehistoria y Arqueología, 3, 9-24.

Ayala, M. (1990): "Estudio preliminar de ritual funerario calcolítico en la comarca de Lorca, Murcia", Zephyrus, 43,77-86. 
Beguiristain, M. A. y Etxeberría, F. (1994): "Lesión craneal seguida de supervivencia en un individuo del dolmen de Aizibitia (Cirauqui, Navarra)", Cuadernos de Arqueología de la Universidad de Navarra, 2, 49-69.

Beguiristain, M. A. (2007): "Memoria de excavación e inventario demateriales del dolmen de Aizibita (Cirauqui, Navarra)", Cuadernos de Arqueología de la Universidad de Navarra, 15, 43-142.

Beguiristain, M. A., Sesma, J. y García, J. (2010): "Formas funerarias en la Prehistoria reciente del Pirineo Occidental". Actas del Congreso Interacional sobre Megalitismo y otras manifestaciones funerarias contemporáneas en su contexto social, económico y cultural, Munibe, Suplemento, 32, 226-248.

Beguiristain, M. A. (2011): “Armas líticas en dólmenes navarros”. VII Congreso General de Historia de Navarra. Príncipe de Viana, LXXII, 253, 43-62.

Bernáldez-Sánchez, E., Bernáldez-Sánchez, M. y García Viñas, E. (2013): ¿“Campos de Hoyos”, Campos de compost?. Estudio tafonómico y paleobiológico del sector de La Gallega del yacimiento de Valencina de la Concepción (Sevilla). En L. García Sanjuan; J. M. Vargas Jiménez; V. Hurtado Pérez; T. Ruiz Moreno y Cruz-Auñón Briones (eds.), El asentamiento prehistórico de Valencina de la Concepción (Sevilla). Sevilla: Universidad de Sevilla, 421-443.

Blasco; C.; Liesau, C.; Delibes, G.; Baquedano., E. y Rodríguez Cifuentes, M. (2005): “Enterramientos campaniformes en ambiente doméstico: el yacimiento de Camino de las Yeseras (San Fernando de Henares, Madrid)", El Campaniforme en la Península Ibérica y su contexto europeo. Valladolid: Universidad de Valladolid, 457-479.

Blasco C.; Delibes, G.; Baena, J.; Liesau, C. y Ríos, P. (2007): "El poblado calcolítico de Camino de las Yeseras (San Fernando de Henares, Madrid). Un escenario favorable para el estudio de la incidencia campaniforme en el interior peninsular", Trabajos de Prehistoria, 6,1, 151-163.

Blasco, C. y Ríos, P. 2010): "La función del metal entre los grupos campaniformes. Oro versus cobre". El ejemplo de la Región de Madrid", Trabajos de Prehistoria, 67, 2, 359-372

Blasco, C.; Liesau, C.; Ríos, P.; Blanco, J. F.; Aliaga, R.; Moreno, E. y A. Daza, A. (2009): "Kupferzeitliche Siedlungsbestattungen mit Glockenbecher - und Prestigebeigaben aus dem Grabenwerk von el Camino de las Yeseras (San Fernando de Henares, prov. Madrid). Untersuchungen zur Typologie des Grabritus und zu dessen sozialer Symbolik", Madrider Mitteilungen, 50, 40-69.

Blasco, C.; Liesau, C. y Ríos, P. (eds.) (2011): Yacimientos calcolíticos con campaniforme de la Región de Madrid. Nuevos estudios. Madrid: UAM, Patrimonio Arqueológico de Madrid, 6.

Blasco, C. y Ríos, P. (2011): "Enterramientos múltiples en un yacimiento con recintos de fosos: un ejemplo en territorio madrileño", Boletín de la Asociación Española de Amigos de la Arqueología, 46 (2010-2011). Homenaje a D. Manuel Santonja Alonso, 67-83.

Botella, M.; Alemán, I. y Jiménez, S. (2000): Los huesos humanos. Manipulación y alteraciones. Barcelona: Eds. Bellaterra.

Brothwell, D. (1987): Desenterrando huesos. La excavación, tratamiento y estudio de los restos del esqueleto humano. México: Fondo de Cultura Económica.

Campillo, D. (1977): Paleopatología del cráneo en Cataluña, Valencia y Baleares. Barcelona: Editorial Montblanc-Martin.

Campillo, D. (1992): “Cicatrización del hueso craneal”. Munibe (Antropologia-Arkeologia), 8 (Suppl.): 33-49.

Campillo, D. (1993-1994): Paleopatología. Los primeros vestigios de la enfermedad. 2 vols. Barcelona: Eds. Bellaterra. Fundación Uriach 1838 Campillo, D. (2007): La trepanación prehistórica. Barcelona: Bellaterra.

Campillo, D.; Mercadal, O. y Blanch, M. ${ }^{a}$ R. (1993): “A Mortal Wound Caused by a Flint Arrowjead in Individual MF-18 of the Neolithic Period Exhumed at Sant Quirce del Valles", International Journal of Osteoarchaeology, vol 3, 145-150.

Cardoso, J. L. (2008): "The chalcolithic fortified site of Leceia (Oeiras, Portugal)", Verdolay, Revista del Museo Arqueológico de Murcia, 11, 49-66.

Cardoso, J. L. (2010): "Povoado pré-histórico de Leceia (Oeiras): evolução arquitectónica do sistema defensivo e das técnicas constructivas correlativas". Gonçalves, V. y Catarina Sousa, A. (eds.), Transformação e Mudança no Centro e Sul de Portugal: o $4^{\circ}$ e o $3^{\circ}$ milenios a.n.e. Cascais: Câmara Municipal.

Case, H. (2004): "Beakers and the Beaker Culture". En J. Czebreszuk (ed.), Similar but Different. Bell Beakers in Europe. Poznan: A. Mickiewicz University, 11-34.

Chambon, P. y Leclerc, J. 2007: "Les tombes multiples dans le Néolithique français : aléa statistique ou pratique institutionnalisée ?", Bulletin de la Société Prehistorique Française. 104, 2, 289-306. 
Chapman, R. (1981): “Los Millares y la cronología relativa de la Edad del Cobre en el Sudeste de España", Cuadernos de Prehistoria de la Universidad de Granada, 6, 75-89.

Chapman, R. (1999): "The origins of warfare in the prehistory of central ans eastern Europe”. In J. Carman and A. Harding (eds.), Ancient Warfare. Stroud: Sutton, 101-142.

Chapman, R. (2008): "Producing Inequalities: Regional Sequences in Later Prehistoric Southern Spain", Journal World Prehistory, 21, 195-260.

Delibes, G. (2011): El pan y la sal. La vida campesina en el valle medio del Duero hace cinco mil años. Real Academia de Bellas Artes de la Purísima Concepción de Valladolid. Valladolid.

Delibes, G. y Pardo, J. S. (1997): "Las fortificaciones de la Edad del Cobre en la Península Ibérica". En VVAA, 1997, 85-107.

Delibes, G.; Díaz-Andreu, M.; Fernández-Posse, C. M.; Montero, I.; Muñoz, I. K. y Ruiz, A., (1996): "Poblamiento y desarrollo cultural en la cuenca de Vera durante la prehistoria reciente", Complutum Extra 6, 153-170.

Delibes, G.; Crespo Díez, M.; Fernández Manzano, J.; Herrán Martínez, J. I. y Rodríguez Marcos, J. A. (2009): "Un recinto de fosos calcolítico en el valle medio de Duero: El Casetón de la Era (Villalba de los Alcores, Valladolid)". Actas de las Cuartas Jornadas de Patrimonio Arqueológico en la Comunidad de Madrid. Dir. Gral. Patrimonio Histórico y Museo Arqueológico Regional, 241-250.

Delibes, G.; Crespo, M.; Fernández Manzano, J.; Herrán, J. I. y Rodriguez Marcos, J. A. (2009): “Stonehenge en Tierra de Campos? Excavaciones en el yacimiento de la Edad del Cobre de El Casetón de la Era (Villalba de los Alcores, Valladolid)", Conocer Valladolid, 15-33.

Deselaers, H. (1917): “Cráneos eneolíticos de Ciempozuelos”, Boletín de la Real Academia de la Historia LXXI, 18-38.

Díaz-del-Río, P. (2003): "Recintos de fosos del III milenio AC en la Meseta peninsular", Trabajos de Prehistoria, 61, 2, 61-78.

Díaz-del-Río, P. (2006): “An appraisal of social inequalities in Central Iberia (c.5300- 1600 CAL BC". En P. Díaz-del-Río y L. García-Sanjuán (eds.), Social Inequality in Iberian Late Prehistory. British Archaeological Reports Internacional Series 1525, 67-79.

Díaz-del-Río, P. (2008): "El contexto social de las agregaciones de población durante el Calcolítico Peninsular", ERA Arqueologia, 8, 128-137.

Díaz-Andreu, M. (1995): "Complex societies in Copper and Bronze Age Iberia: a reappraisal”, Oxford Journal of Archaeology, 14, 23-33.

Driesch, A. von den (1972): Osteoarchaologische Untersuchungen auf der Iberischen Halbinsel. Studien über frühe Tierknochenfunde von der Iberischen Halbinsel 3. Munich.

Boessneck, J. (1976): “Die Fauna vom Castro Do Zambujal”. Studien über frühe Tierknochenfunde von der Iberischen Halbinsel, 5, 1-129.

Boessneck, J. (1981): “Die Fauna von Zambujal”. En Sangmeister, E. y H. Schubart, 303-314.

Esparza, A.; Delibes, G.; Velasco, J. y Cruz, P. J. (2008): "Historia de un golpe en la cabeza: sobre el enterramiento calcolítico del hoto 197 de "El Soto de Tovilla" (Tudela de Duero, Valladolid)". BSAA Arqueología, LXXIV, 9-48.

Etxeberria, F. y Vegas, I. (1988): “¿Agresividad social o guerra? durante el Neo-eneolítico en la cuenca media del Valle del Ebro, a propósito de San Juan Ante Portam Latinam (Rioja alavesa)", Munibe (Antropología y Arqueología) Suplemento, 6, 105-112.

Etxeberria, F. y Herrasti, L. (2007): "Los restos humanos del enterramiento de San Juan ante portam latinam (Laguardia, Alava). Caracterización de la muestra, Tafonomía y Paleopatología)". En Vegas (dir.), 159-280.

Fabián, J. F. (2006): El IV y III milenio AC en el Valle del Amblés (Avila). Arqueología de Castilla y León. Monografías, 5: Junta de Castilla y León.

Fabián, J. F. y Blanco, A. (2012): "Cuatro enterramientos calcolíticos en hoyo del Cerro de la Cabeza", Complutum, 23 (1), 99-120.

Fernández Díaz, J. M. (2000): "La trepanación y cirugía de cráneo en el antiguo Perú (I)”. Revista de Arqueología, XXI, 230, 42-53.

Fernandez Manzano, J. y Montero, I. (1997): "Las armas durante el Calcolítico y la Edad del Bronce". En VVAA, 1997, 109-121.

Galindo, L. y Sánchez, V. M. (2007): "El Soto de Henares y sus recintos”. Actas de las terceras Jornadas de Patrimonio Arqueológico en la Comunidad de Madrid. Museo Arqueológico Regional 29-30 de noviembre 2006. Alcalá de Henares, 413-416. 
García García, M. (2013): "Las Pozas (Casaseca de las Chanas, Zamora): dos nuevos recintos de fosos calcolíticos en el Valle del Duero". Trabajos de Prehistoria, 70, 1, 175-184.

Gibaja, J. F.; Terradas, X.; Palomo, A. y Clop, X. (2009): "Las grandes láminas de sílex documentadas en contextos funerarios del Neolítico Final - Bronce Inicial en el Nordeste peninsalar". Les grans fulles de sílex. Europa al final de la Prehistòria. Actes. Monografies 13. Barcelona: Museu d' Arqueología de Catalunya, 63-68.

Gómez, J. L.; Blasco, C.; Trancho, G.; Ríos, P.; Grueso, I. y Martínez, M. ${ }^{a}$ S. (2011): “Los protagonistas". En Blasco, Liesau y Ríos (eds.), Yacimientos calcolíticos con campaniforme de la Región de Madrid. Nuevos estudios. Madrid: UAM, Patrimonio Arqueológico de Madrid, 6, 100-132.

Gómez, J. L. (2012): "Sobre las enfermedades infecciosas en paleopatología”, 25-33. En Daschner y Gómez (eds.), Medicina Evolucionista: Aportaciones pluridisciplinares, volumen I.

Gómez, J. L. y Grueso I. (2011): Estudio antropológico del fondo U.Ex. 455. Yacimiento de Humanejos (Parla, Madrid). Informe inédito.

Gostner, P. y Egarter Vigl, E. (2002): "Insight: Report of Radiological-Forensic Findings on the Iceman", Journal of Archaeological Science, 29, 323-326.

Guilaine, J. y Zammit, J. (2002): El camino de la Guerra. Barcelona: Ariel Prehistoria (2a ed.).

Haas, J. (1999): "The origins of war and ethnic violence". In J. Carman and A. Harding (eds.), Ancient Warfare. Stroud: Sutton, 11-24.

Hain, F. H. (1982): Kupferzeitliche Tierknochenfunde aus Valencina de la Concepción. Studien über frühe Tierknochenfunde von der Iberischen Halbinsel 8. Munich.

Herrerín, J. (2004): Paleopatología. Necrópolis de El Burgo de Osma (c. XVII-XVIII). Soria: Soria Edita.

Hurtado, V. (2004): "El asentamiento fortificado de San Blas (Cheles, Badajoz)", Trabajos de Prehistoria, 61, 1, 141-155.

Isidro, A. y Malgosa, A. (2003): Paleopatología. La enfermedad no escrita. Barcelona: Masson, S. A.

Jiménez-Brobeil, S. A.; Souich, Ph. du and Al Oumaoui, I. (2009): "Possible Relationship of Cranial Traumatic Injuries With Violence in the South-East Iberian Peninsula From the Neolithic to the Bronze Age", American Journal Of Physical Anthropology, 140, 465-475.

Jorge, S. O. (1994): "Colónias, fortificaçoes, lugares monumentalizados. Trajétoria das concepçoes sobre um tema do calcolítico peninsular", Revista da Facultade de Letras, II Serie, vol. XI, 447-546.

Jorge, S. O. (2003) (coord.): Recintos murados da Pre-histoira Recente. Porto-Coimbra.

Kunst, M. (2000): “A guerra no calcolítico na península ibérica”, Era-Arqueología, 2, 128-142.

Kunst, M. (2007): Seit wann gibt es Krieg?. En S. Burmeister, H. Derks y J. von Richthofen (eds.). Festschrift für Michael Gebühr zum 65. Geburtstag: Marie Leidorf GmbH. Rahden/Westf, 123-138.

Kunst, M. y Lutz, N. (2008): "Zambujal (Torres Vedras, Portugal). Zur Präzision der absoluten Chronologie durch Untersuchungen an der vierten Befestigungslinie", Madrider Mitteilungen, 49, 29-63.

Leisner, G. (1943): Die Megalithgräber der Iberischen Halbinsel. Band I. Der Süden. Berlín: Römisch Germanische Forschungen, 17.

Lemercier, O. (2011): "Le guerrier dans l'Europe du III' millènaire avant notre ère. L'arc et le poignard dans les sépultures individuelles campaniformes". En L. Baray; M. Honegger y M. H. Dias-Meirinho (dirs.). L'armement et l'image du guerrier dans les sociétés anciennes. Dijon, 121-165.

Liesau, C. (2011): "Los restos de mamíferos del ámbito doméstico y funerario". En Blasco, C., Liesau, C. y Ríos, P. (eds.), 171-189.

Liesau von Lettow-Vorbeck, C. y Pastor Abascal, I. (2003): “The Ciempozuelos Necropolis Skull: A Case of Double Trepanation?", International Journal of Osteoarchaeology, 13, 213-221.

Liesau, C.; Blasco, C.; Ríos, P.; Vega, J.; Menduiña, R.; Blanco, J. F.; Baena, J.; Herrera, T.; Petri, A. y Gómez, J. L. (2008): "Un espacio compartido por vivos y muertos: El poblado calcolítico de fosos de Camino de las Yeseras (San Fernando de Henares, Madrid)", Complutum, vol 18.1, 97-120.

Lomba, J.; Salmerón, J. y Báguena, J. C. (1995): "El enterramiento colectivo calcolítico de los Grajos III (Cieza, Murcia)", Memorias de Arqueología, 92-106.

Márquez, B.; Gibaja, J. F.; González, J. E.; Ibañez, J. J. y Palomo, A. (2009): “Projectile points as signs of violence in collective burials during the $4^{\text {th }}$ and the 3 rd millennia cal. $\mathrm{BC}$ in the North-East of the Iberian Peninsula". http://hdl.handle.net/10261/10203.

Márquez, J. E. y Jiménez, V. (2010): Recintos de Fosos. Genealogía y significado de una tradición en la Prehistoria del suroeste de la Península Ibérica (IV-III milenios AC). Málaga: Universidad de Málaga. 
Museo de Almería, en red: Colecciones en Red de Ceres: http.ceres.mcu.es (acceso 17/09/2012). Madrid: Ministerio de Educación, Cultura y Deporte.

Molina, F. y Cámara, J. (2005): Los Millares. Guía del yacimiento arqueológico. Sevilla: Junta de Andalucía, Consejería de Cultura.

Molina González, F.; Contreras Cortés, F.; Ramos Millán, A.; Mérida González, V.; Ortiz Risco, F. y Ruiz Sánchez, V. (1986): "Programa de recuperación del registro arqueológico del Fortín 1 de Los Millares. Análisis preliminar de la organización del espacio", Arqueología Espacial, 8, 175-201.

Monks, S. (1999): "Patterns of warfare and settlement in southeast Spain", Journal of Iberian Archaeology, 1, 127-171.

Nájera, T.; Molina, F.; Jiménez, S.; Al Oumaoui, I.; Roca, M.; Haro, M. y Fernández, S. (2010): "Un ejemplo de violencia interpersonal extrema durante la Edad del Bronce: el enterramiento 60 de La Motilla del Azuer", Cuadernos de Prehistoria y Arqueología de la Universidad de Granada, n. 20 , 381-394.

Navas, E.; Molina, F. y Esquivel, J. A. (2005):“La distribución espacial de los restos faunísticos de Los Millares (Santa Fe de Mondújar, Almería)", Complutum, 16, 89-104.

Nocete, F. (coord.) (2004): ODIEL, Proyecto de la investigación arqueológica para el análisis del origen de la desigualdad social en el suroeste de la Península Ibérica. Monografías arqueológicas 19. Sevilla: Junta de Andalucía.

Pajuelo Pando, A. y López-Aldana, P. (2013): "Estudio arqueozoológico de estructuras significativas de C/Mariana de Pineda s/n (Valencina de la Concepción, Sevilla)". En García Sanjuan, L. Vargas Jiménez, J. M.; Hurtado Pérez, V.; Ruiz Moreno, T. Cruz-Auñón Briones (eds.), El asentamiento prehistórico de Valencina de la Concepción (Sevilla). Sevilla: Universidad de Sevilla, 445-458.

Palomo, A. y Gibaja, J. F. (2002): "Análisis de las puntas del sepulcro calcolitico de la Costa de Can Martorell (Dosrius, Barcelona)”. En I. Clemente, R. Risch y J. F. Gibaja (eds.), Análisis Funcional. Su aplicación al estudio de sociedades prehistóricas. Oxford: British Archaeological Reports IS, 1073, 243-249.

Pérez Fernández, A. (2010): "Signos de violencia en el registro osteoarqueológico". En Pérez y Soler (coord.), 141-154.

Pérez Fernández, A. y Soler, B. (coord.) (2010): Restos de vida, restos de muerte. Exposición "la Muerte en la Prehistoria", Museu de Prehistòria de Vàlencia 4 de febrero al 30 de mayo de 2010.

Pernter, P., Gostner, P., Vigl E. E. y Rühli, F. J. (2007): "Radiologic proof for the Iceman's cause of death (ca. 5'300 BP)". Journal of Archaeological Science 34, 1784-1786.

Peters, J. y Driesch, von den A. (1990): “Archäozoologische Untersuchungen der Tierreste aus der Kupferzeitlichen Siedlung von Los Millares (Prov. Almería)", Studien über frühe Tierknochenfunde von der Iberischen Halbinsel, 12, 51-109.

Polo, M.; García Prósper, E. y Romero, A. (2010): "Bioantropología y Paleopatología. Herramientas para una investigación histórico-arqueológica”. En A. Pérez y B. Soler (coord.), 95-116.

Ramos, J.; Domínguez-Bella, S.; Pérez, M. y Vijande, E. (2009): "Producción, distribución y consumo de los productos líticos laminares vinculados a las sociuedades tribales comunitarias y clasistas iniciales del ámbito atlántico de Cádiz". Les grans fulles de sílex. Europa al final de la Prehistòria. Actes. Monografies 13: Museu d'Arqueología de Catalunya. Barcelona, 25-33.

Ramos Millán, A.; Martínez Fernández, G.; Ríos Jiménez, G. y Alfonso Marrero, J. A. (1991): Flint Production and Exchange in the Iberian Southeast, III millennium B. C. Excursion Guidebook, Granada, Universidad de Granada e ITGME.

Riaño, J. F.; Rada, J. de y Catalina J. (1894): "Hallazgo prehistórico en Ciempozuelos", Boletín de la Real Academia de la Historia, XXV, 436-450.

Ríos, P. (2011): Territorio y Sociedad en la Región de Madrid durante el III milenio a. C. El referente del yacimiento de Camino de las Yeseras. Col. Patrimonio Arqueológico de Madrid, 7. Madrid: Ed. Dpto. Prehistoria y Arqueología - UAM (digital).

Sampedro, C. y Liesau, C. (1998): El yacimiento campaniforme de la Cuesta de la Reina (Ciempozuelos). Los restos antropológicos. En C. Blasco Bosqued; J. Baena Preysler y C. Liesau von LettowVorbeck, La Prehistoria madrileña en el Gabinete de Antigüedades de la Real Academia de la Historia. Los yacimientos Cuesta de la Reina (Ciempozuelos) y Valdocarros (Arganda del Rey). Madrid: Depto. de Prehistoria y Arqueología de la U.A.M. Patrimonio Arqueológico del Bajo Jarama, 3, 34-55 
Sangmeister, E. y Schubart, H. (1981): Zambujal. Madrider Beiträge, 5. Philipp von Zabern: Mainz am Rhein.

Silva, A. M. y Marques, R. (2010): "An arrowhead injury in a Neolithic human axis from the natural cave of Lapa do Bugio (Sesimbra, Portugal)", Anthropological Science, 118,3, 185-189.

Smith, M .J.; Brickley, M. B. \& Leach, S. L. (2007): "Experimental evidence for lithic projectile injuries: improving identification of an under-recognised phenomenon", Journal of Archaeological Science, 34, 540-553.

Spindler, K. (1995): El hombre de los hielos. Barcelona: Galaxia Gutenberg.

Stodiek, U. y Paulsen, H. (1996): Mit Pfeil und Bogen". Technik der steinzeitlichen Jagd. Archäologische Mitteilungen aus Nordwestdeutschland. Beiheft, 16. Oldenburg: Isensee Verlag.

Sudhues, H. (2004): Wundbalistik bei Pfeilverletzungen. Inaugural-Dissertation zur Erlangung des doctor medicinae. Münster: Westfälische Wilhelms-Universität.

Thorpe, I.J.N. (2005): "The ancient origins of warfare and violence". Warfare, Violence and Slavery in Prehistory. British Archaeological Report. International Series, 1374, 1-18.

Ubelaker, D. (2007): “Enterramientos humanos: Excavación, análisis, interpretación”, Munibe, suplemento . $^{\circ} 24$.

Uerpmann, H.- P. y Uerpmann, M. (2003): Zambujal. Die Stein und Beinartefakte aus den Grabungen 1964-1973. Madrider Beiträge, 5. Zambujal Teil 4. Mainz.

Valera, A. C. (2003): "A propósito de recintos murados do $4^{\circ}$ e $3^{\circ}$ milenios a. C.: dinámica e fixação do discurso arqueológico". En Jorge S.O. (ed.), Recintos Murados da Pré-historia Recente. Porto, 149-168.

Valera, A. C. (2008): "Intervenção arqueológica de 2007 no interior do recinto Pré-Histórico dos Perdigões (Reguengos de Monsaraz)". Apontamentos de Arqueologia e Património, 1, 15-22.

Valera, A. C., Santos, H., Figueiredo, M. y Granja, R. (e.p): "Contextos funerários na periferia do Porto Torrão: Cardim 6 e Carrascal 2". Actas do IV Colóquio Arqueológico de Alqueva. Beja, 2010.

Vega, J.; Blasco, C.; Liesau, C.; Ríos, P.; Blanco, J. F.; Menduiña, R.; Aliaga, R.; Moreno, E.; Herrera T.; Petri, A. y Gómez, J. L. (2010): "La singular dualidad de enterramientos en el poblado de silos calcolítico de Camino de las Yeseras (San Fernando de Henares, Madrid)", Munibe Suplemento. Actas del Congreso Internacional sobre Megalitismo y otras manifestaciones funerarias contemporáneas en su contexto social, económico y cultural, 11 al 15 de Junio de 2007. Beasain: Idiazabal (Guipúzcoa).

Vega, J.; Blasco, C.; Menduiña, R.; Ríos, P.; Petri, A. y Herrera, T. (2009): "El poblado de fosos del yacimientos de Camino de las Yeseras (San Fernando de Henares)". Actas de las Cuartas Jornadas de Patrimonio Arqueológico en la Comunidad de Madrid. Madrid: Dir. Gral. Patrimonio Histórico y Museo Arqueológico Regional, 251-261.

Vegas, J. I. (dir) (2007): San Juam ante portam latinam. Una inhumación colectiva prehistórica en el Valle del Ebro. Vitoria-Gasteiz: Museo de Arqueología de Alava.

Vegas, J. I. (2007): "El yacimiento, descubrimiento e investigación”. En Vegas (dir.), San Juan ante Portam Latinam. Memorias de Yacimientos Alaveses, 12, 17-54.

Vencl, S. L. (1984): "War and Warfare in Archaeology". Journal of Anthropological Archaeology, 3, 116-132.

VVAA (1997): La guerra en la Antigüedad. Una aproximación a los orígenes de los ejércitos en Hispania. Madrid, Ministerio de Defensa.

Recibido: 01/09/2012

Aceptado: 12/06/2014 